PontifícIa Universidade CATÓLICA do RIO DE JANEIRO

\title{
Uma comparação entre Fundos de Investimentos ESG e Tradicionais no mercado de capitais brasileiro.
}

LUIS GUILherme Mambrini Santos Moreira Pinto

Trabalho de Conclusão de Curso

CENTRO dE CIÊNCIAS SOCIAIS - CCS

Departamento de AdMinistração

Graduação em Administração de Empresas 


\section{Luis Guilherme Mambrini Santos Moreira Pinto}

\section{Uma comparação entre Fundos de Investimentos ESG \\ e Tradicionais no mercado de capitais brasileiro. \\ Trabalho de Conclusão de Curso}

Trabalho de Conclusão de Curso, apresentado ao programa de graduação em Administração da PUCRio como requisito parcial para a obtenção do título de graduação em Administração.

Orientador(a): Marcelo Klötze

Rio de Janeiro

Junho de 2021 


\section{Resumo}

Uma comparação entre fundos ESG e Fundos de Investimentos Tradicionais no mercado de capitais brasileiro. Trabalho de Conclusão de Curso - Departamento de Administração. Pontifícia Universidade Católica do Rio de Janeiro.

Nos últimos anos, estamos passando por uma transformação no mercado de capitais brasileiro, onde o número de investidores ingressando na bolsa de valores e em investimentos de maior risco vem crescendo desenfreadamente, em razão dos títulos de renda fixa atrelados ao CDI não estarem atrativos como anteriormente. Portanto, os brasileiros, acostumados com a cultura de taxas de juros altas, estão precisando mudar sua cultura de investir para obter maiores retornos e junto a isso, surgem os fundos de investimentos conhecidos como ESG (Environmental, Social and Corporate Governance), e diferentemente dos fundos de investimentos tradicionais, são aplicações que buscam conciliar o retorno financeiro e fomentar uma melhora na sociedade na qual fazemos parte. Este trabalho apresenta dados através da realização de um backtest da performance de fundos de investimentos e faz o cálculo de indicadores essenciais para realizar qualquer tipo de análise de fundos, para posteriormente identificar se no mercado atual, os fundos sustentáveis apresentam desempenho melhor ou pior do que investimentos tradicionais.

Palavras- chave: Bolsa de Valores. Investidor. ESG. 


\section{Sumário}

1 Introdução ao tema e contexto atual de mercado ............................. 6

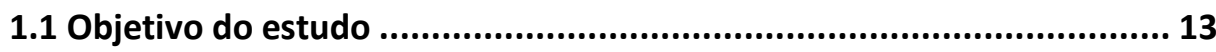

1.2 Delimitação e foco do estudo ............................................................. 13

1.3 Justificativa e Relevância do Estudo................................................... 13

2. Referencial Teórico .............................................................. 14

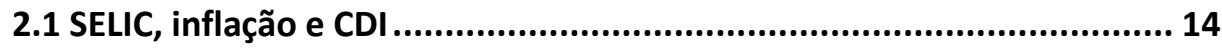

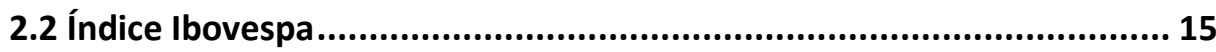

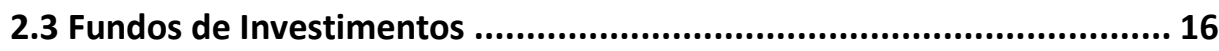

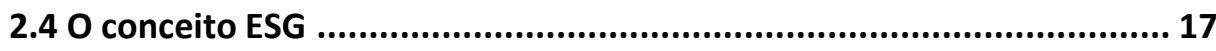

2.5 ISE B3 - Índice de Sustentabilidade Empresarial ................................. 19

2.6 Riscos de mercado (Liquidez, Mercado, Crédito) ............................... 20

2.7 Risco Sistemático e Não Sistemático................................................. 20

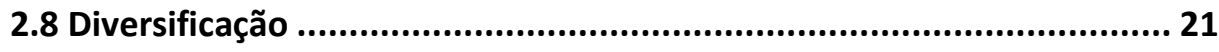

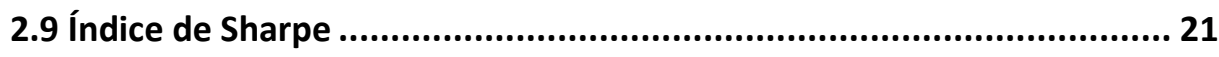

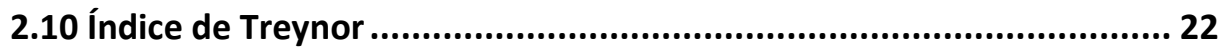

2.11 Rentabilidade Relativa e Absoluta ................................................. 23

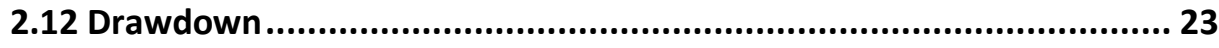

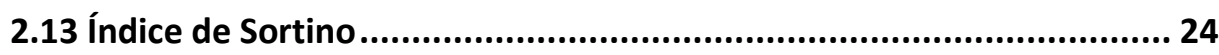

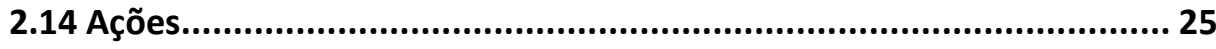

2.15 Oferta Pública de Ações (IPO e Follow-on) ....................................... 25

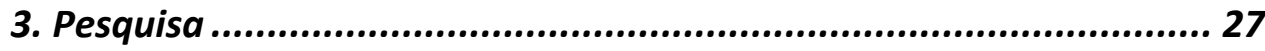

3.1 Procedimento de Coleta dos Dados .................................................... 27

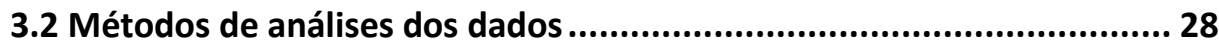

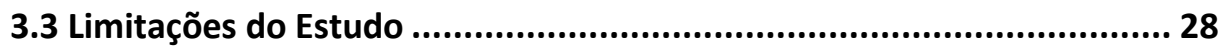

4 Apresentação e análise dos resultados......................................... 29

4.1 Seleção das Gestoras de Recursos e Fundos ........................................ 29 


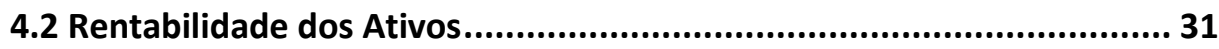

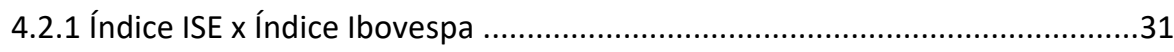

4.2.2 Constellation Compounders x Bahia AM Valuation FIC AÇÕES........................33

4.2.3 Bradesco FIA Sustentabilidade Empresarial x SANTANDER SELEÇÃO CRESCIMENTO FIC AÇÕES . .39

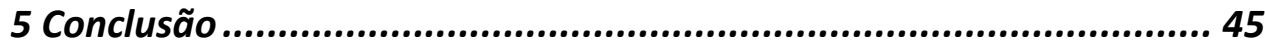

Referências bibliográficas ................................................... 47 


\section{Índice de Tabelas}

Tabela 1: Produtos financeiros mais usados pelos investidores .............................. 6

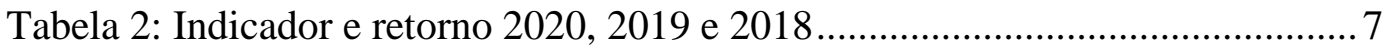

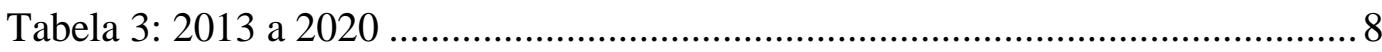

Tabela 4: retorno acumulado 1/1/2015 a 21/12/2020 _............................................ 8

Tabela 5: Evolução no número de investimentos de reda variável nos últimos 10

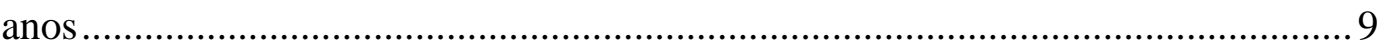

Tabela 6: Google Trends: Busca pelo termo "ESG" no mundo ............................ 10

Tabela 7: Evolução do AuM em investimento sustentável .................................. 10

Tabela 8: Percentual do AuM em investimento sustentável.................................. 11

Tabela 9: Evolução do AuM dos signatários do PRI .............................................. 12

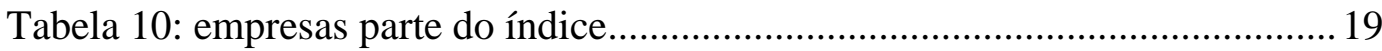

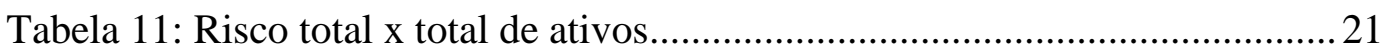

Tabela 12: Rentabilidade absoluta x CDI X Rentabilidade relativa ao CDI......... 23

Tabela 13: Empresas x performance desde o IPO ...............................................26

Tabela 14: Rentabilidade absoluta dos índices Ibovespa e do Índice de

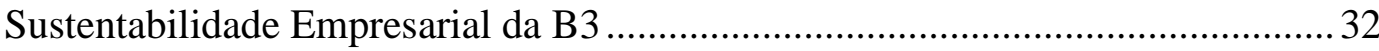

Tabela 15: Retorno acumulado 1/12019 a 30/4/2021 ........................................... 32

Tabela 16: Constellation Compounders x Bahia AM Valuation FIC AÇÕES ..... 33

Tabela 17: Retorno acumulado 1/1/2019 a 30/4/2021 .......................................... 34

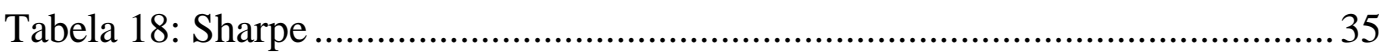

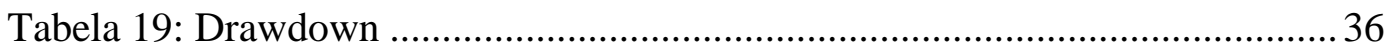

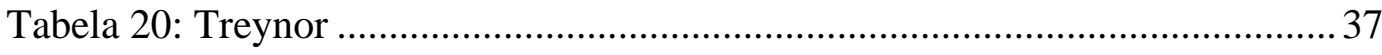

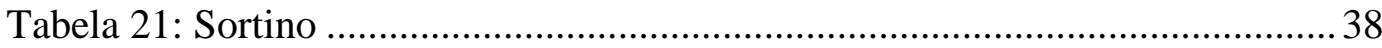

Tabela 22: Bradesco FIA Sustentabilidade Empresarial x SANTANDER

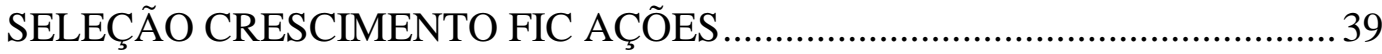

Tabela 23: retorno acumulado 1/1/2019 a 30/4/2021 ............................................ 40

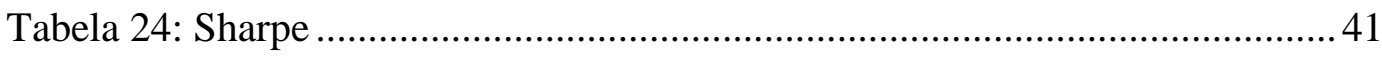

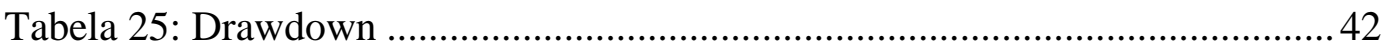

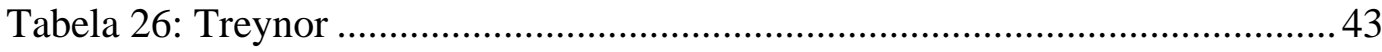

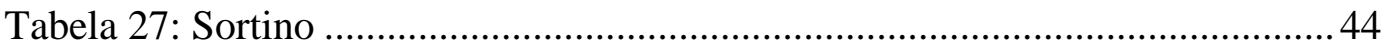




\section{Introdução ao tema e contexto atual de mercado}

Historicamente, o Brasil possuiu uma taxa básica de juros e inflação altas, seja por questões políticas, econômicas ou fiscais, fazendo com que investimentos atrelados ao CDI e ao IPC-A, que são indexadores diretamente influenciados pela SELIC, tivessem seus rendimentos sempre muito atrativos. No entanto, atualmente, nos deparamos com um cenário completamente diferente, no qual temos uma taxa de juros em um de seus menores níveis históricos, quando em março de 2021, o COPOM fixou em 2,75\% a a e isso vem afetando como o investidor brasileiro pensa seus investimentos.

Segundo estudo realizado pela ANBIMA, em 2020, a poupança segue sendo o produto preferido entre os investidores no Brasil e cerca de $84 \%$ da população ainda tem caderneta de poupança dentro do portfólio de investimentos. Em segundo lugar aparecem os fundos de investimentos com 6\%, seguido pela previdência privada e por títulos privados com 5\%, os títulos públicos representam $4 \%$, ações $3 \%$ e moedas estrangeiras apenas $2 \%$.

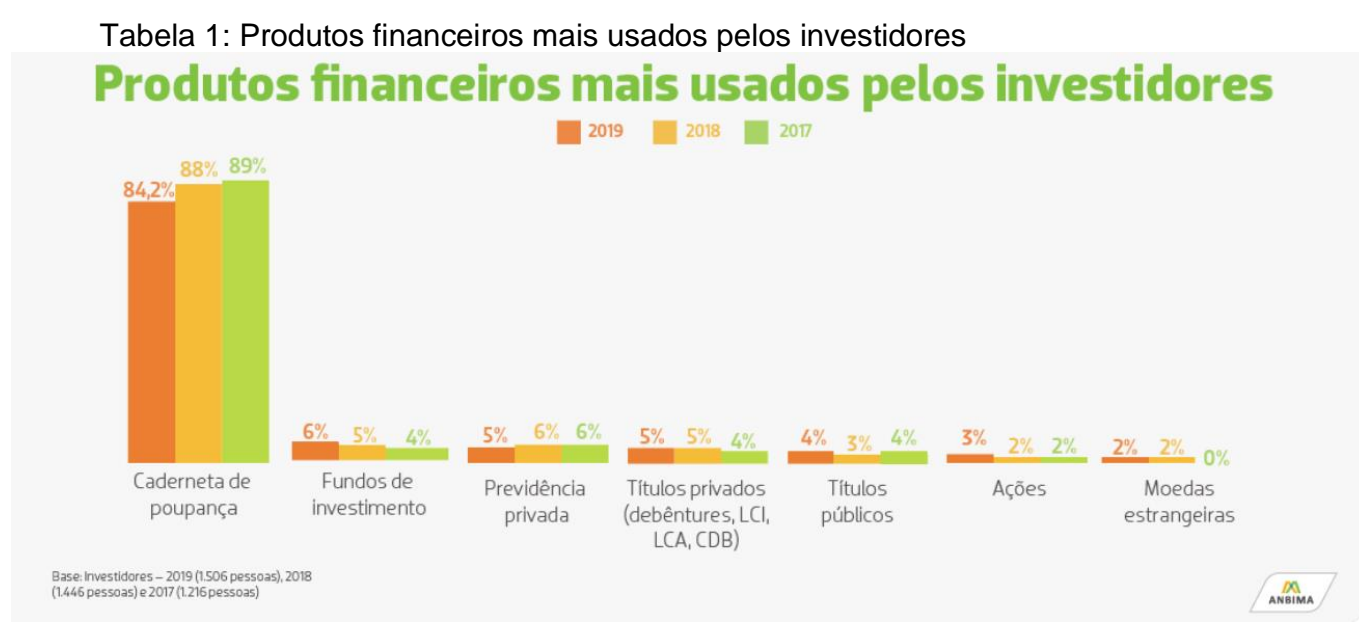

Fonte: https://www.anbima.com.br/pt_br/especial/raio-X-do-investidor-2020.htm

Observando esses dados, notamos que o investidor brasileiro ainda concentra seus investimentos em ativos de baixo risco, por mais que estes apresentem retornos menores nos patamares atuais e até mesmo, considerando a inflação atual, gerem um retorno real negativo. A parcela que investe em renda variável ainda é pequena, mas de 2018 para 2019, mais do que dobrou. 
Hoje, existem investimentos acessíveis, de baixo risco e com rentabilidades superiores a poupança.

Tabela 2: Indicador e retorno 2020, 2019 e 2018

\begin{tabular}{|c|c|c|c|}
\hline Indicador & \multicolumn{3}{|c|}{ Retorno (\%) } \\
\hline Dólar & $\mathbf{2 0 2 0}$ & $\mathbf{2 0 1 9}$ & $\mathbf{2 0 1 8}$ \\
IPCA & $\mathbf{2 8 , 9 3}$ & 4,02 & 17,13 \\
Ibovespa & 2,52 & 4,31 & 3,75 \\
Poupança (Selic) & 2,11 & 31,58 & 15,03 \\
\hline
\end{tabular}

Tendo em vista essa diminuição da SELIC desde 2017 e o baixo retorno oferecido pelos títulos de renda fixa, cada vez mais o mercado está se expandindo e se digitalizando e, nos últimos anos, o interesse do brasileiro pela bolsa de valores e investimentos com grau de risco maior aumentou. Nos últimos anos houve uma migração mais forte da renda fixa para a renda variável por parte dos investidores brasileiros, visto que em 2017 era possível adquirir títulos do governo com rendimentos de $7 \%$ ao ano e atualmente os mesmos títulos possuem um rendimento de $2,75 \%$, fazendo com que tal aplicação não seja mais atrativa do ponto de vista do investidor que busca maiores retornos e até mesmo negativa considerando a inflação, que em 2020 foi de 4,52\%.

Porém, a parcela dos investidores que se arrisca diretamente na bolsa ainda é pequena, segundo a última pesquisa realizada pela B3, 2020 encerrou com 3.174.090,00 investidores, representando pouco mais de $1,5 \%$ da população brasileira e um número insignificante se comparado com outros países que possuem mercado mais desenvolvido.

No gráfico abaixo, considerando 2013 a 2020, observamos que o CDI ganhou do Ibovespa em rentabilidade até 2018. Contudo, com a diminuição do indexador e a alta da bolsa, esse número mudou e o comportamento do mercado também, fazendo com que as pessoas migrassem seus investimentos para outros ativos. 
Tabela 3: 2013 a 2020

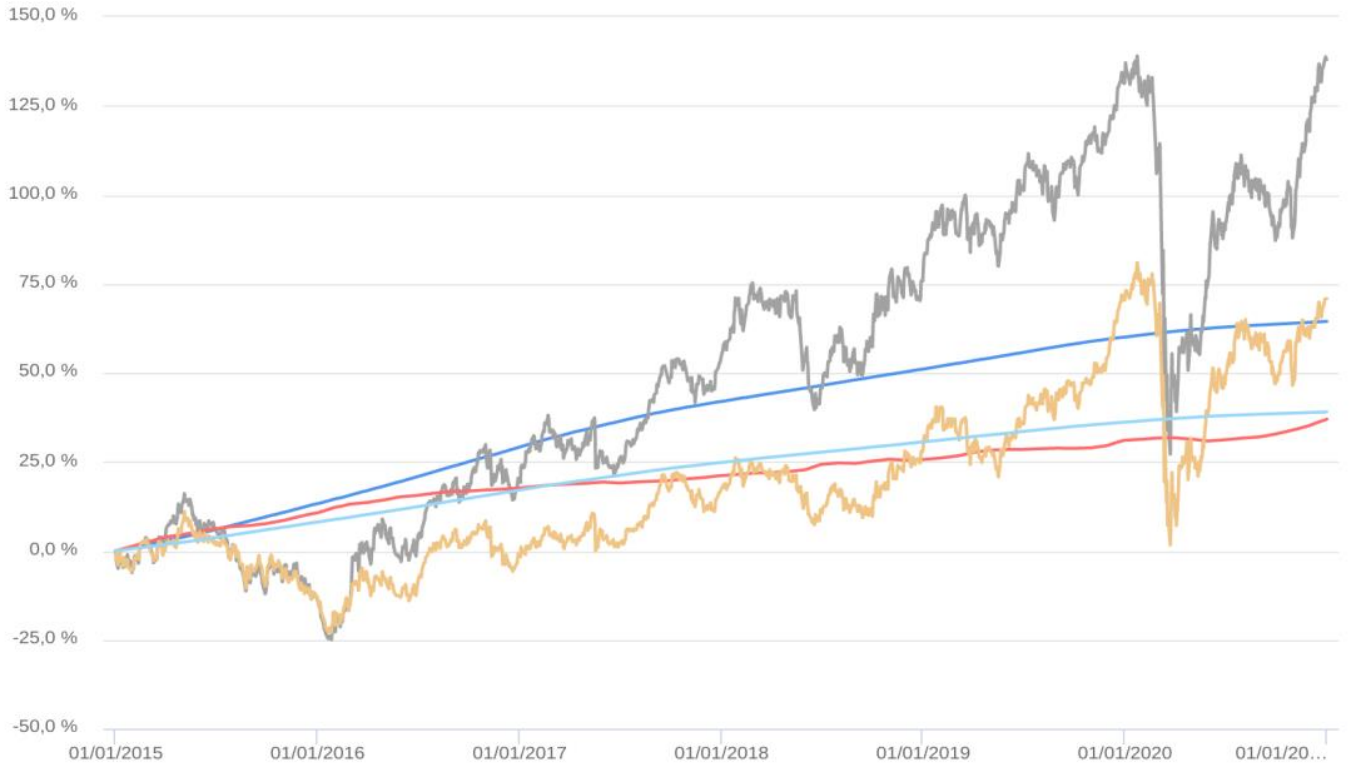

Fonte: Gráfico Elaborado no Excel através de dados retirados do Quantum Axis.

Tabela 4: retorno acumulado 1/1/2015 a 21/12/2020

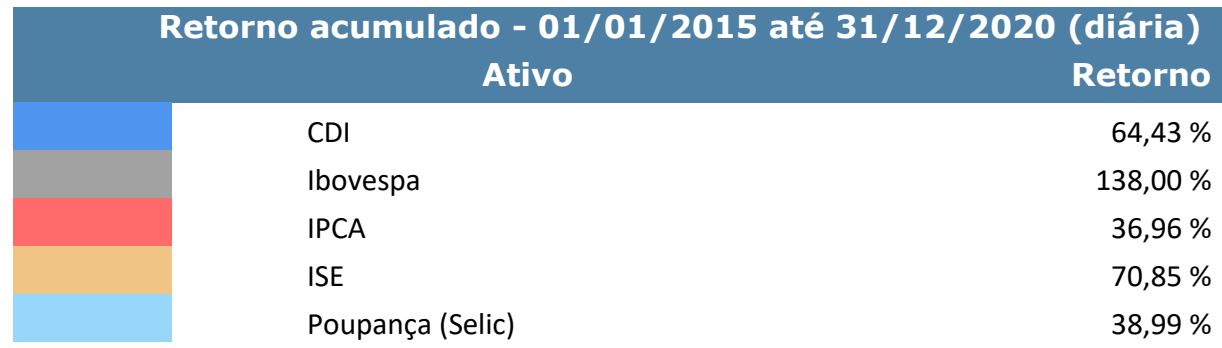

Fonte: Elaboração própria no Excel e dados retirados do Quantum Axis. 
Tabela 5: Evolução no número de investimentos de reda variável nos últimos 10 anos Evolução no número de investidores đe renda variável nos últimos 10 anos:

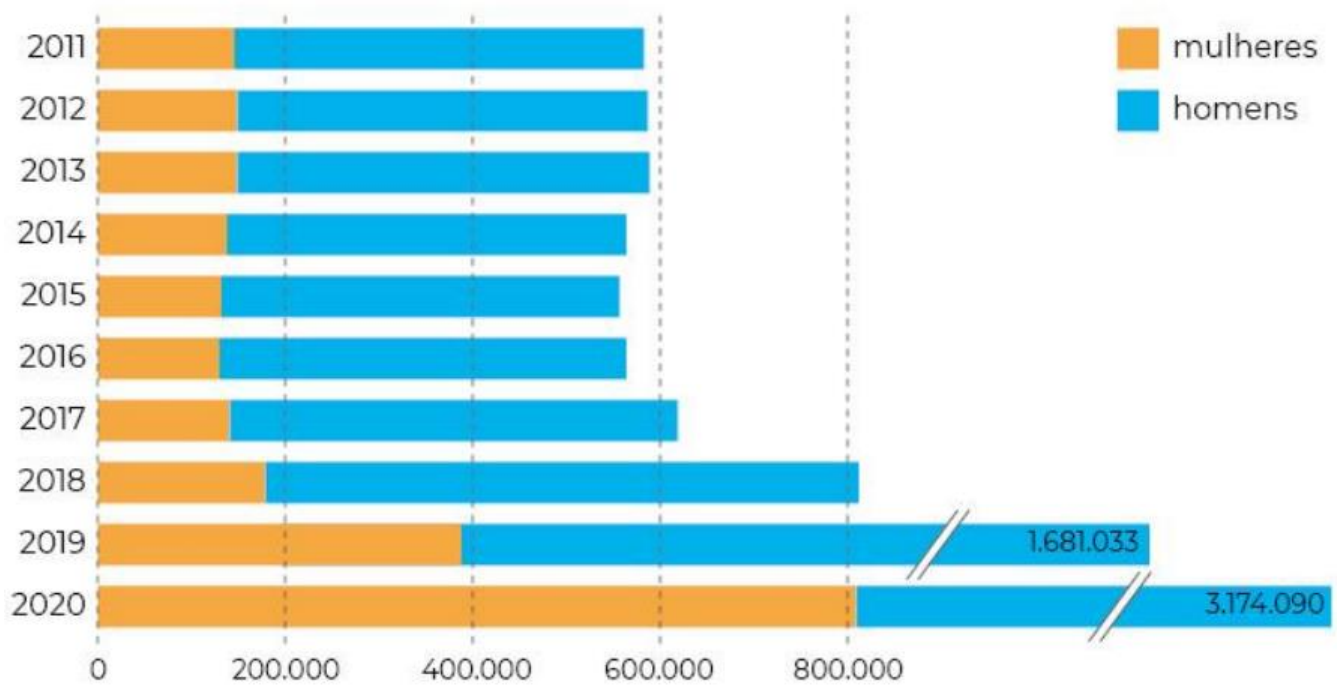

Fonte: A DESCOBERTA DA BOLSA PELO INVESTIDOR BRASILEIRO -

Site da B3.

Junto a esse movimento de maior interesse pela renda variável no país, um tema já conhecido no exterior passou a ganhar importância no cenário nacional, a saber: a gestão ESG. As empresas, fundos e produtos de investimento com o carimbo ESG são aqueles que buscam gerar impactos positivos atuando nas três frentes propostas no contexto, que são Environmental, Social e Governance, ou seja, possuem uma preocupação com a preservação do meio ambiente, com pautas sociais e com boas práticas de governança corporativa.

Portanto, no caso dos fundos de investimentos, é dever do gestor assumir um dever fiduciário com seus clientes de, ao montar um portfólio ESG, buscar empresas que estejam alinhadas com os princípios do tema e que gerem uma rentabilidade esperada dentro do controle de risco estipulado.

Segundo pesquisa da XP, houve um crescimento exponencial nas pesquisas sobre o tema no Google Trends. 
Tabela 6: Google Trends: Busca pelo termo "ESG" no mundo

Gráfico Google Trends*: Busca pelo termo "ESG" no mundo

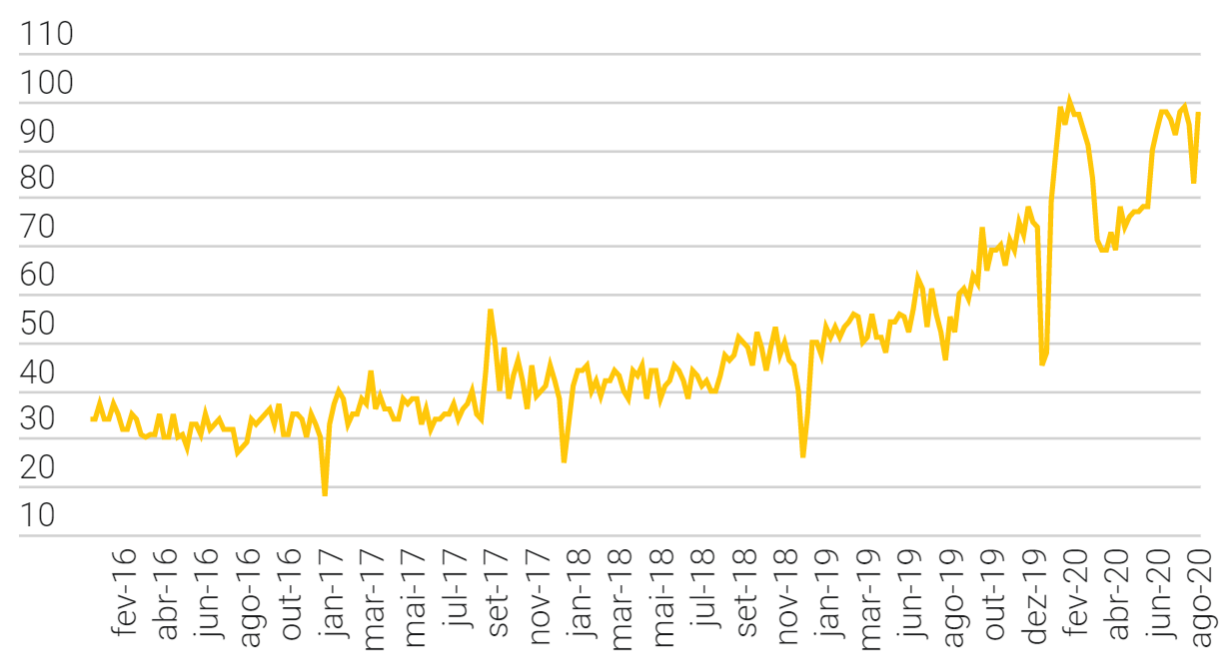

Fonte: Google Trends, XP Investimentos

*Os números representam o interesse de pesquisa relativo ao ponto mais alto no gráfico. Um valor de 100 representa o pico de popularidade de um termo.

Globalmente, segundo pesquisa feita pela XP e Global Sustainable Investment Alliance, mais de US\$30 trilhões em ativos sob gestão são gerenciados por fundos que definiram estratégias sustentáveis. Representando um aumento de $34 \%$ em relação a 2016.

Tabela 7: Evolução do AuM em investimento sustentável Gráfico Evolução do AuM em investimento sustentável (US\$̦tri)

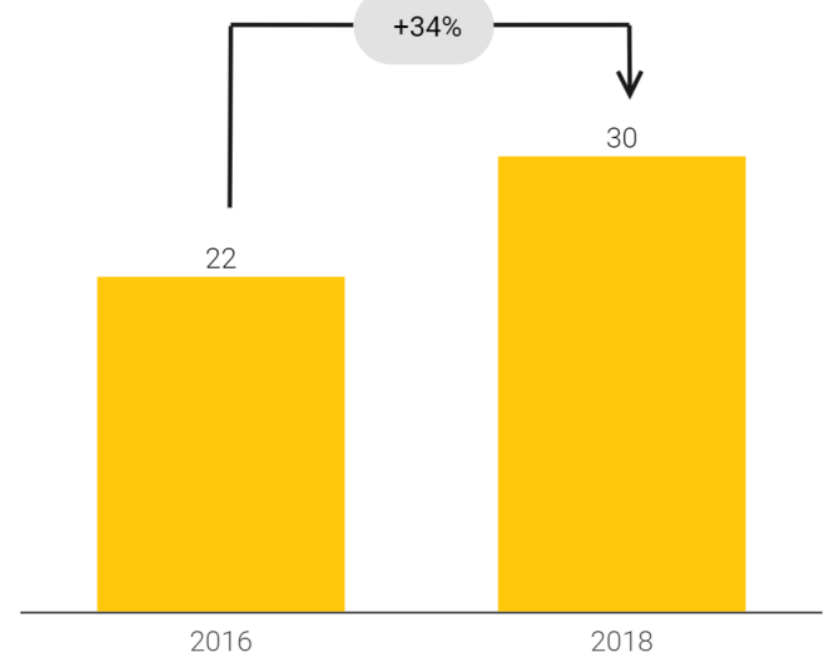

Fonte: Global Sustainable Investment Alliance, XP Investimentos 
Grande parte dos ativos sustentáveis sob gestão ficam na Europa, sendo esse mercado responsável por US\$14,1 trilhões e seguido por Estados Unidos e Japão, que juntos representam $26 \%$ e $18 \%$, respectivamente. Porém, o cenário é de crescimento nesses dois países, desde 2016 o percentual vem aumentando consideravelmente, saltando de $26 \%$ para $36 \%$ nos Estados Unidos e de $3 \%$ para $18 \%$ no Japão.

Tabela 8: Percentual do AuM em investimento sustentável

Gráfico Percentual do AuM em investimento sustentável
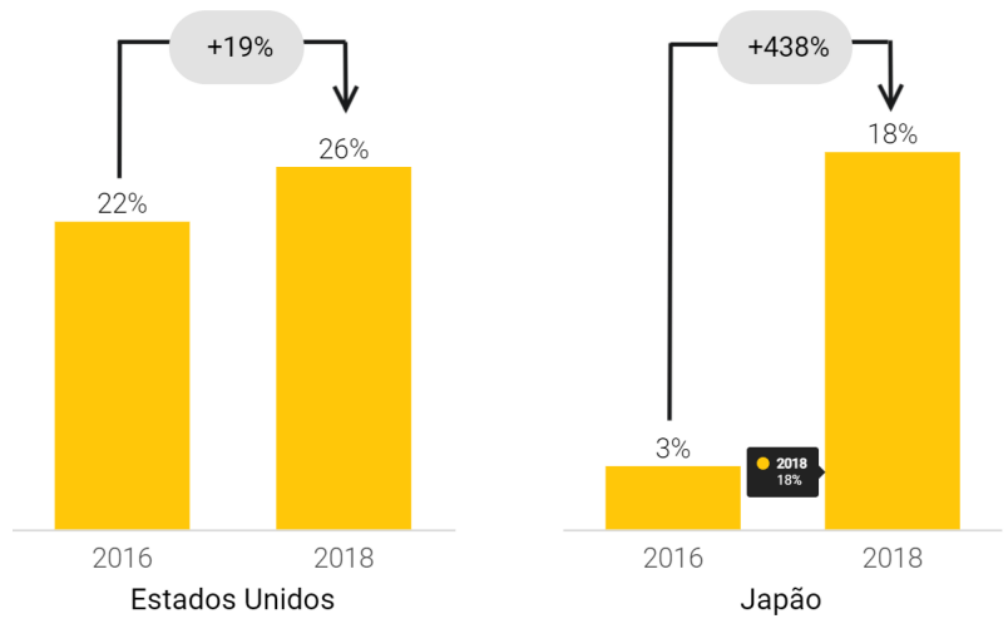

Fonte: Global Sustainable Investment Alliance, XP Investimentos

Outro dado que demonstra a evolução e procura dos investidores por portfólio ESG é o número de signatários do PRI (Principles for Responsible Investment ou Princípios para o Investimento Responsável), organização fundada em 2006, liderada pela Organização das Nações Unidas (ONU) e que tem como objetivo representar o compromisso dos seus signatários, dos mercados financeiros e das economias de investir em negócios sustentáveis no longo prazo. 
Tabela 9: Evolução do AuM dos signatários do PRI

Gráfico Evolução do AuM dos signatários do PRI e \# de signatários

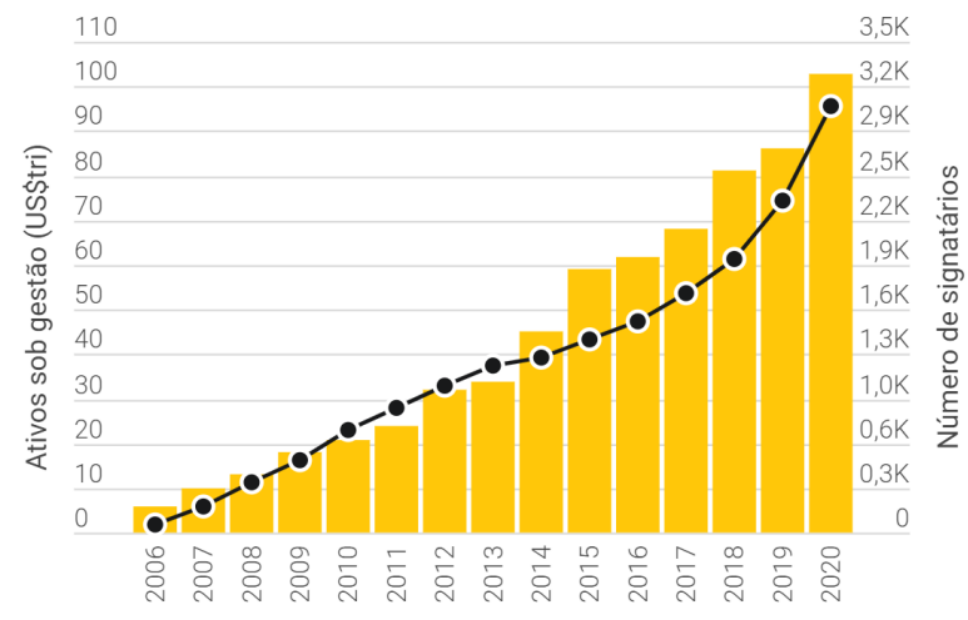

Ativos sob gestão (US\$̦tri)

Número de signatários

Fonte: PRI (Principles for Responsible Investment), XP Investimentos

Observando o gráfico, notamos que o número de signatários do PRI vem crescendo e já passa dos 3000 membros, sendo esses signatários responsáveis por representar mais de US\$100 trilhões.

No Brasil, instituições de grande porte estão ancorando esse crescimento da cultura no mercado, como a XP Investimentos, que promoveu pela primeira vez, em 2021, um evento digital totalmente voltado para o assunto ESG e facilitou o acesso aos produtos sustentáveis.

Isso demonstra que o mercado brasileiro passou por uma revolução tecnológica nos últimos anos, fazendo com que hoje o acesso a bons investimentos seja mais democrático. Assim, uma série de corretoras estão no segmento, sem tarifas de manutenção de contas e sem dificuldades ao operacionalizar uma abertura, como todas do Grupo XP, BTG Pactual, Órama e ModalMais. Ao consultar a plataforma de produtos disponíveis em cada uma delas, produtos ESG são oferecidos em todas, apesar da limitação dos gestores ao montar o portfólio, já que por enquanto, poucas empresas listadas em bolsa são sustentáveis.

Junto ao surgimento dessas corretoras, outras plataformas surgiram nos últimos anos para motivar e ajudar o investidor brasileiro, como os aplicativos TradeMap e Traders Club, que além da apresentação de dados de empresas listadas, distribuição de relatórios de investimentos e oportunidade de cursos, também 
permitem a interação entre investidores e promovem eventos com gestores e personalidades com experiência no mercado financeiro nacional.

\subsection{Objetivo do estudo}

Em um momento em que os juros no Brasil estão próximos do menor patamar da história, a procura por investimentos mais rentáveis vem aumentando e junto a isso, a preocupação com fazer bem ao meio ambiente e a sociedade.

Dessa forma, a procura do investidor por investimentos sustentáveis, com uma boa relação de risco e retorno vem aumentando no Brasil, uma vez que na Europa e Estados Unidos já é rotineira.

\subsection{Delimitação e foco do estudo}

Realizar um backtest dos fundos classificados como ESG, fazer a comparação com investimentos tradicionais e com o Ibovespa, que não possuem como base principal o conceito de investimento sustentável e possuem dentro de sua composição, qualquer tipo de empresa.

\subsection{Justificativa e Relevância do Estudo}

O estudo pretende demonstrar se no cenário atual do mercado brasileiro, os produtos brasileiros classificados como ESG estão conseguindo superar a rentabilidade de investimentos que não possuem essa preocupação na montagem do portfólio.

Ao analisar o estudo realizado, o novo investidor poderá identificar se faz sentido, a partir da rentabilidade, investir em produtos sustentáveis e para o investidor que já tem posição, se o retorno obtido nos anos anteriores foi expressivo. 


\section{Referencial Teórico}

\subsection{SELIC, inflação e CDI}

Segundo Assaf Neto (2014), a taxa básica de juros, popularmente conhecida como SELIC, é a representação da média dos financiamentos lastreados em títulos públicos federais e sua apuração é feita diariamente pelo Sistema Especial de Liquidação e Custódia.

O Comitê de Política Monetária (COPOM), que é um órgão vinculado ao Banco Central (BC), por meio de reuniões periódicas, tem o poder de fazer alterações na taxa SELIC e apresentar um viés de aumento ou redução de juros para o próximo período e assim, estabelecer os parâmetros da política monetária. A taxa definida pelo COPOM serve como base para todas as instituições do mercado brasileiro.

A inflação, segundo Assaf Neto, é um fenômeno que pode ser interpretado como uma variação nos preços gerais da economia durante um determinado período, ou seja, é o aumento do preço dos bens e serviços disponíveis, que ao decorrer do tempo ocasiona a perda de capacidade de compra da moeda, diminuindo assim o poder aquisitivo dos agentes econômicos. Portanto, essa diferença é notada pela variação de preço no dia a dia desses bens e serviços e cada economia mede sua própria inflação.

O índice utilizado majoritariamente no Brasil é o Índice de Preços ao Consumidor Ampliado (IPCA), que é conhecido como um percentual médio da variação dos preços de determinados bens e serviços, comparado com períodos anteriores e calculado pelo IBGE. Outro índice conhecido é o Índice Geral de Preços do Mercado (IGPM), que é utilizado principalmente em contratos de aluguel e em tarifas de energia, podendo ser classificado com um indexador de contrato e medidor das alterações de preços de bens e serviços no mercado brasileiro, mas diferentemente do IPCA, ele é calculado pela FGV.

É importante para o investidor que deseja manter sua capacidade de consumo estar atento ao IPCA, tendo em vista que ele reflete o aumento ou diminuição dos bens e serviços consumidos diariamente por toda a população, e como dito anteriormente, em patamares de SELIC baixa, os juros reais acabam 
sendo negativos, sendo a inflação maior do que a taxa de juros. Portanto, tornando investimentos anteriormente atrativos, nos patamares atuais esse cenário é diferente.

O CDI, é um título emitido pelos bancos para a realização de operações de empréstimo entre si, com prazo de 24 horas. Surgindo a partir de trocas financeiras realizadas por bancos ao final do dia, ela lastreia as operações interbancárias que os bancos precisam realizar para manterem seus caixas positivos no caso de haver mais saques do que depósitos, sendo essa uma regra do Banco Central. Portanto, se um banco está negativo ao final do dia, a instituição emite um Certificado de Deposito Bancário (CDI) para tomar um empréstimo com outro banco e regularizar a situação.

O CDI é uma importante ferramenta para o sistema financeiro nacional, sendo ele uma garantia de que o investidor terá liquidez para efetuar um eventual saque e assim manter o equilíbrio do sistema financeiro. Além disso, como as operações realizadas entre bancos possuem um risco de crédito muito baixo, o CDI acabou se tornando um benchmark livre de risco, sobretudo para ativos de renda fixa. Por isso, é comum vermos títulos atrelados à taxa DI, sendo essa a média do valor cobrado nas operações de CDI.

\section{2 Índice lbovespa}

Segundo site oficial da B3 (2021), atualmente ele é o principal indicador de desempenho das ações negociadas na B3 e reúne as empresas mais importantes e negociadas no mercado de capitais brasileiro. O índice foi criado em 1968 e mais de 50 anos é referência para investidores no mundo todo.

Atualmente, são 77 ações de 74 empresas diferentes que fazem a composição do índice, e o peso de cada uma é determinado de acordo com o volume de negociação de cada uma. As maiores representações do índice são: Vale (VALE3) (10,53\%), Itaú (ITUB4) (6,170\%), Petrobras (PETR4) (5,559\%), B3 (B3SA3) $(5,446 \%)$ e Bradesco (BBDC4) $(4,806 \%)$. 


\subsection{Fundos de Investimentos}

De acordo com Assaf Neto (2014), fundos de investimentos são um conjunto de recursos monetários, formados por depósitos de investidores, chamados de cotistas, e que se destinam à aplicação coletiva em uma carteira de títulos e valores mobiliários.

Esses fundos representam uma grande quantidade de investidores e tem como vantagem oferecer aos cotistas a administração dos recursos monetários de maneira profissional, sem necessidade de que os investidores tenham que dominar algum tipo de técnica de análise para investir, além de, por operarem em volumes financeiros altíssimos, os fundos poderem obter condições mais favoráveis de negociação do que uma pessoa física conseguiria operando sozinha no mercado.

Cada fundo possui um regulamento e um prospecto, que passam a ser disponíveis para todo cotista a partir do ingresso e esses documentos definem informações relevantes, como tipos de ativos que comporão sua carteira e limites máximos de \% de uma classe ativos no portfólio.

Caso tenha a necessidade de se tomar alguma decisão que envolva a participação dos cotistas, são criadas assembleias, e elas deliberam sobre assuntos como alterações no administrador, taxa de administração e prazo de liquidação do fundo.

O Gestor de carteira de um fundo é o responsável por selecionar os ativos que vão compor a carteira, levando em consideração sempre a estrutura da carteira e seu risco, ele é o representante dos cotistas na tomada de decisão do mercado. O gestor deve ser credenciado na CVM para exercer a função.

Em grande parte dos fundos, duas taxas são cobradas, a taxa de administração, que é um percentual fixo sobre o valor total da aplicação de cada cotista, independente do resultado, e a taxa de performance, que é cobrada com base no desempenho apresentado pela carteira do fundo.

Basicamente, há duas estratégias de investimentos predominantes no mercado: a gestão ativa de um fundo, que envolve a compra e venda de ativos, obtendo retornos acima de um benchmark previamente estipulado e uma gestão passiva, na qual o gestor investe em uma carteira que busca seguir algum índice de mercado existente, nessa segunda estratégia, o retorno deve aproximar-se ao 
máximo desse indicador e ela costuma apresentar custos menores de administração e performance.

Para investidores que muitas vezes não possuem conhecimento ou tempo para acompanhar o mercado financeiro, o investimento em fundos é a melhor opção, já que os profissionais fazem uma gestão de risco e vivenciam o dia a dia do mercado, além de conseguirem acessar diferentes mercados, como em outros países.

Os fundos de investimento são classificados de acordo com a composição de suas carteiras, o conceito de ESG é utilizado principalmente em fundos multimercados e de ações. Os fundos de ações devem conter na sua carteira uma posição de $67 \%$ comprada em ações no mercado a vista, muitas vezes tem como benchmark um índice de mercado de ações, como o Ibovespa, a variação da cota acompanha a variação dos ativos que fazem parte do portfólio e podem ser constituídos como fundos abertos ou fechados. Diferentemente, os fundos multimercados não possuem a obrigação de concentrar um percentual específico de uma classe de ativos no portfólio, ou seja, possuem maior liberdade na gestão, o que facilita a diversificação do portfólio.

\subsection{0 conceito ESG}

Segundo Marta Pinheiro (2020), diretora de ESG (Environmental Social and Governance) da XP Investimentos, o conceito é uma forma de analisar investimentos, não só considerando a relação risco e retorno, mas também avaliando o impacto socioambiental e de governança corporativa que cada uma das empresas costuma aplicar no dia a dia. De acordo com o CFA Institute (2020), ao avaliar os investimentos em empresas, é necessário observar a questão ambiental interna no dia a dia de trabalho, se os funcionários estão satisfeitos no cotidiano, e em relação ao meio ambiente e como os investimentos impactam nos recursos naturais como emissões de gases, poluição, biodiversidade, gestão de resíduos e efluentes. Na parte social, como os colaboradores e parceiros são tratados, as condições de trabalho que os funcionários estão submetidos, a diversidade na força de trabalho e a interação com a comunidade local. A questão da governança ocorre observando a transparência, os processos que a empresa desempenha e como ela é 
gerida, questões como remuneração dos executivos e políticas contábeis também são levadas em consideração.

Existem algumas estratégias de investimentos ESG praticadas no mercado, Helena Masullo (2020), Head de Estratégia ESG da XP Private, destaca conceitos como Negative Screening, isto é, a estratégia na qual os investidores deixam de investir em um determinado ativo pelo fato dessa compra não estar alinhada com o que eles acreditam, costuma ocorrer com empresas de bebidas alcoólicas ou de tabaco. Outra estratégia é a Best In Class, quando o investidor busca selecionar as companhias com as melhores práticas ESG em um determinado setor, acreditando que essas companhias vão performar melhor no médio e longo prazo. $\mathrm{O}$ ativismo acionário é outra abordagem utilizada por investidores, nela, o investidor que possui um percentual relevante da companhia tem poder de voto em assembleias e assim pode interferir nas ações ESG praticadas pela empresa. Segundo o BlackRock Investment Institute, organização criada por uma das maiores gestoras de recursos do mundo, a abordagem mais conhecida é a Interação ESG, que é a utilização de pesquisas, dados e perspectivas em decisões de investimentos e que possui como objetivo ajudar o gestor de portfólios a tomar essas decisões levando em consideração informações ESG financeiramente relevantes, aprimorando o processo de alocação e implementando cada vez nos portfólios distribuídos pela gestora.

O greenwashing é um termo utilizado no contexto ESG, e pode ser utilizado por governos, empresas, ONGs e se trata de uma propaganda enganosa. Ocorre quando uma empresa promove uma ação para ganhos reputacionais, mas internamente comete práticas que não são coerentes com o posicionamento externo, fazendo ações apenas visando fins de marketing.

No mercado de fundos, o exterior já possui diversas opções de fundo ESG por ser um mercado de investimentos mais maduro. No Brasil, esse mercado ainda está começando, contudo, renomadas gestoras de recursos já possuem dentro do portfólio de produtos, estratégias focadas integralmente em investimentos sustentáveis. Esses fundos podem ser multimercados, de ações, private equity, e podem possuir uma gestão ativa, aquela em que os gestores integram ativamente as estratégias ESG na montagem do portfólio, ou gestão passiva, que seguem um determinado ETF do mercado. 


\subsection{ISE B3 - Índice de Sustentabilidade Empresarial}

A criação do ISE foi uma inciativa pioneira na América Latina e segundo a B3, criadora do indicador, tem como objetivo criar um ambiente de investimento compatível com as demandas de desenvolvimento sustentável da sociedade e estimular a responsabilidade ética das corporações.

Segundo reportagem do Valor Econômico, em 2021 a B3 já atualizou a carteira do Índice de Sustentabilidade Empresarial (ISE B3), que tem como missão auxiliar os investidores na tomada de decisão ao investir e incentivar as empresas a praticarem melhores práticas ESG.

Atualmente, a carteira possui 46 ações, de 39 empresas e 15 setores diferentes e tem como novos entrantes Petrobras, M. Dias Branco, Cosan, GPA, Marfrig, CPFL, Minerva, Suzano, BTG e Neoenergia. Abaixo, todas as outras empresas que fazem parte do índice:

Tabela 10: empresas parte do índice

\begin{tabular}{|c|c|c|c|c|}
\hline AES Tiete & Cemig & Eletrobras & $\begin{array}{c}\text { Lojas } \\
\text { Bmericanas }\end{array}$ & Neoenergia \\
\hline $\begin{array}{c}\text { Banco do } \\
\text { Brasil }\end{array}$ & Cielo & Engie & Lojas Renner & Petrobras \\
\hline BR & Cosan & GPA & Marfrig & Suzano \\
\hline Distribuidora & Branco & Santander \\
\hline Bradesco & CPFL & Itaú Unibanco & Minerva & Telefônica \\
\hline BRF & Duratex & Itaúsa & Movida & Tim \\
\hline BTG & Ecorodovias & Klabin & MRV & Weg \\
\hline CCR & EDP & Light & Natura & \\
\hline
\end{tabular}

Fonte: Site Oficial da B3. 


\subsection{Riscos de mercado (Liquidez, Mercado, Crédito)}

Todas as operações de investimentos no mercado financeiro estão sujeitas a riscos e dependendo da classe do produto, esses riscos são maiores ou menores.

Existem três principais riscos. O primeiro é o risco de crédito, segundo Assaf Neto (2014) é o risco de o investidor não receber o valor principal investido e nem os juros pagos por conta de eventual deterioração da qualidade do crédito ou da situação financeira do emissor, responsável pelo pagamento da dívida. No mercado, esse risco é explicado pelas seguintes origens:

- Não pagamento da dívida (default) por parte do devedor.

- Risco de país que deriva principalmente de aspectos regulatórios, políticos e econômicos.

- Carteira de crédito com baixa diversificação, elevando o risco pela concentração dos contratos em termos de perfil do devedor, setor de atividade ou região.

Ainda segundo Assaf Neto, o risco de mercado é o segundo risco que existe em relação a oscilação das condições de mercado que podem gerar perdas ao investidor e até comprometer o valor investido. Ele depende muitas vezes de cenários macroeconômicos que afetam inflação, taxas de juros, indicadores de bolsas de valores, preços de commodities.

E por último, o risco de liquidez, no qual o investidor pode sofrer perda de parte do valor investido caso necessite se desfazer de determinado ativo antes do prazo de vencimento.

\subsection{Risco Sistemático e Não Sistemático}

Segundo Assaf Neto (2014), o risco de um ativo é mensurado pela variabilidade dos retornos projetados pelo investidor.

No mercado, a única coisa que temos certeza é que não existe um investimento completamente seguro. Portanto, é necessário conhecer esses riscos e saber diferenciar esses dois conceitos.

Sabendo distinguir, a estratégia de investidor pode mudar a qualquer momento, sabendo minimizar ou aumentar exposição à algum investimento. 
O risco sistemático é aquele que afeta toda a economia, como uma pandemia, uma grande variação nas taxas de juros ou no câmbio, ele é ocasionado por uma eventual catástrofe no sistema financeiro.

Já o não sistemático está ligado a uma empresa ou setor específico, e nesse caso, sendo ele o único que pode ser minimizado com uma estratégia conhecida como diversificação.

Tabela 11: Risco total $x$ total de ativos

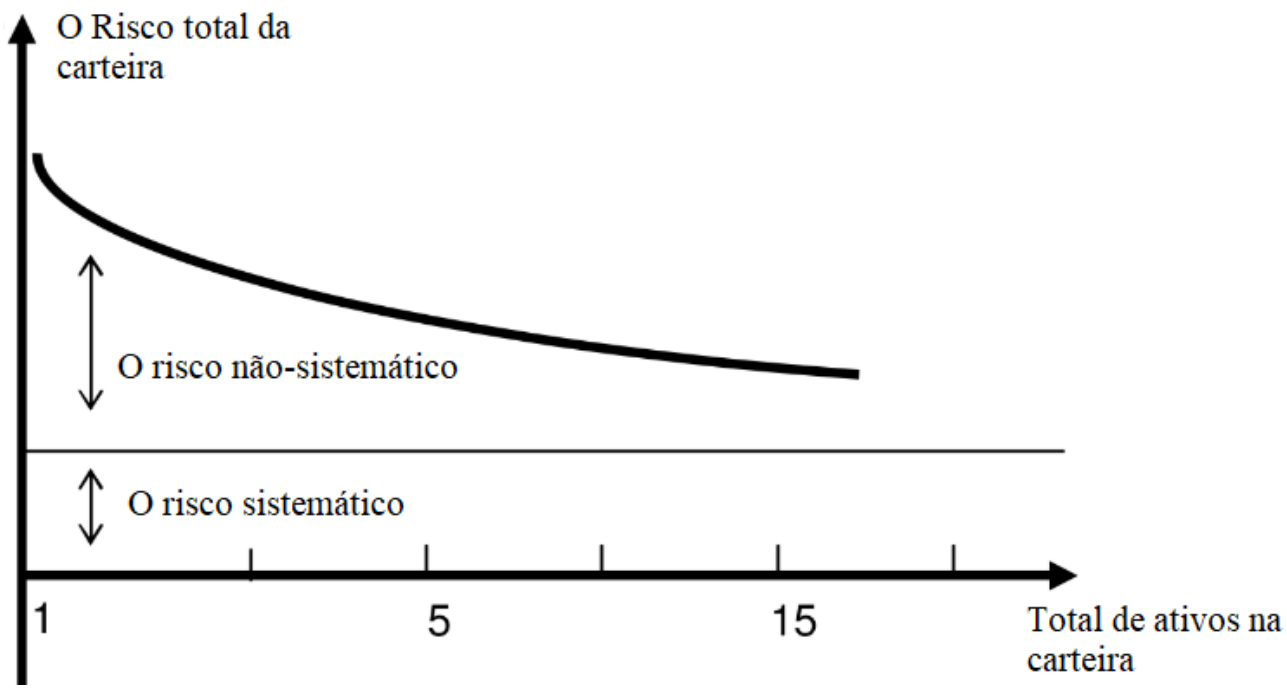

Fonte: Administração Financeira: Teoria e Prática Brigham e Ehrhardt (2012)

\subsection{Diversificação}

A diversificação de investimentos é uma técnica elaborada para diluir os riscos de um determinado portfolio e maximizar os ganhos potenciais. Para isso, deve-se alocar os recursos em diversos segmentos de ativos, que sejam descorrelacionados entre si e respeitando o perfil do investidor, de maneira que o desempenho negativo de um ativo não signifique perdas definitivas para a carteira.

\section{9 Índice de Sharpe}

O índice de Sharpe é uma medida de avaliação de risco e retorno, e é apresentado utilizando a relação entre o prêmio pago pelo risco assumido e o risco do próprio investimento (Assaf Neto, 2014). 
Para calcular, são utilizadas três medidas: retorno esperado de uma carteira constituída por ativos com risco, o desvio-padrão (risco) dessa carteira e a taxa de juros livre de risco, que no Brasil é o CDI. Com esse índice, é possível obter o prêmio oferecido por um ativo para cada percentual de risco assumido.

Com esses dados, utiliza-se a fórmula abaixo para calcular o índice de Sharpe:

$$
\mathrm{IS}=(\mathrm{Ri}-\mathrm{Rf}) /(\sigma \mathrm{i})
$$

Sendo Ri o retorno do ativo analisado, Rf o retorno livre de risco e o desvio padrão é o risco do ativo.

Ao comparar fundos de investimento, o índice de Sharpe é um dos indicadores mais utilizados, direcionando a decisão do investidor e promovendo uma melhor construção do patrimônio em questão. Basicamente, aplicações com um Sharpe mais alto alcançaram que o rendimento foi obtido com um nível de risco menor e com o resultado mais baixo, risco foram corridos para alcançar determinado retorno.

O retorno livre de risco reflete a rentabilidade de ativos de renda fixa, conservadores e mais seguros de um determinado país, no Brasil, poderíamos considerar a LFT, título do Tesouro atrelado a Selic.

A volatilidade basicamente reflete a intensidade e frequência das flutuações de preço dos ativos em um determinado intervalo de tempo, servindo como referência de risco. Uma alta volatilidade indica uma maior imprevisibilidade no rendimento.

\subsection{0 Índice de Treynor}

Segundo Assaf Neto (2014), esse indicador mostra quanto foi retorno de uma determinada carteira para cada unidade de risco sistêmico assumida e para calcular o índice, utiliza-se a equação abaixo:

$$
\mathrm{Ta}=(\mathrm{Ra}-\mathrm{Rf}) /(\mathrm{Ba})
$$


Sendo Ra o retorno do fundo em questão, $\mathrm{Rf}$ o retorno livre de risco e $\mathrm{Ba}$ a medida de risco sistêmico, representado por Beta.

Assim como no índice de Sharpe, a taxa livre de risco é representada pelo investimento de menor risco disponível no mercado (CDI), o Beta é o risco sistêmico assumido, portanto, é uma medida do risco que um investidor está exposto ao investir em um ativo em particular em comparação com o mercado como um todo e o risco embutido no geral.

\subsection{Rentabilidade Relativa e Absoluta}

Segundo Assaf Neto, todos os fundos possuem um benchmark. No Brasil, os mais comuns são o CDI e o Ibovespa, sendo esses os índices de referência que um fundo deseja acompanhar ou superar, ao longo de sua rentabilidade anual.

A rentabilidade absoluta representa a rentabilidade do fundo em um determinado período, ou seja, é o ganho em relação ao montante principal aplicado, representada em percentual. Já a rentabilidade relativa é expressa em percentual em relação ao benchmark estipulado no regulamento do fundo, ou seja, em fundos que utilizam o CDI, terão sua rentabilidade como base nele.

Tabela 12: Rentabilidade absoluta x CDI X Rentabilidade relativa ao CDI

\begin{tabular}{|r|c|c|}
\hline $\begin{array}{l}\text { Rentabilidade } \\
\text { absoluta }\end{array}$ & CDI & $\begin{array}{c}\text { Rentabilidade } \\
\text { relativa ao CDI }\end{array}$ \\
$6 \%$ & $2,75 \%$ & $218,18 \%$ \\
$9 \%$ & $2,75 \%$ & $327,27 \%$ \\
$12 \%$ & $2,75 \%$ & $436,36 \%$ \\
$15 \%$ & $2,75 \%$ & $545,45 \%$ \\
\hline
\end{tabular}

Fonte: Elaboração própria no Excel com dados obtidos no Quantum Axis.

\subsection{Drawdown}

Segundo Tiago Reis (2019), analista de ações da Suno Research, o drawdown é a representação de quanto um ativo caiu desde sua cotação máxima em um determinado período. Com isso, o investidor pode analisar o quanto ele perdeu no fundo investido em percentual. 
O cálculo do drawdown é feito da seguinte forma:

drawdown $=($ Valor máximo do ativo/Valor mínimo do ativo $)-1$

Sendo:

Valor do máximo = a cotação mais alta de um ativo em uma série histórica.

Valor do mínimo = a cotação mais baixa de um ativo em uma série histórica .

Valores menores nesse indicador provam uma maior estabilidade de um ativo, e vice-versa.

\subsection{3 Índice de Sortino}

Segundo Frank A. Sortino (1980), professor da San Francisco State University, assim como o índice de Sharpe, este índice analisa o desempenho de um determinado fundo com base em uma série de métricas, contudo, ele adota apenas o desvio padrão dos retornos negativos ao invés de utilizar o desvio padrão total dos ativos. $\mathrm{O}$ índice é interessante porque o investidor se importa mais quando tem prejuízo do que quando com o lucro, além de em um mercado de baixa, fundos que possuem um Sortino maior se protegem melhor das quedas.

Para calculá-lo, utiliza-se a seguinte fórmula:

Isa $=((\mathrm{Ri}-\mathrm{Rf}) /(\sigma$ dos retornos negativos $)) *\left((252)^{\wedge}(1 / 2)\right)$

Sendo Ri o retorno do fundo em questão, Rf o retorno livre de risco e $\sigma$ dos retornos negativos o downside risk, ou seja, a variabilidade das perdas abaixo do ativo livre de risco.

Já que o índice usa apenas o desvio negativo como medida de risco, o problema de usar o risco total (desvio padrão) é resolvido, já que a parte positiva do desvio padrão é benéfica para os investidores, modificando a análise. 


\subsection{Ações}

Conforme explicitado por Assaf Neto (2014), ações constituem-se em títulos representativos da menor parte do capital social de uma sociedade empresarial que dá o direito ao acionista de participar dos resultados da companhia.

Ações, diferente de outros investimentos, não possuem um prazo de resgate e podem ser convertidas em dinheiro a qualquer momento, são negociadas na Bolsa de Valores, através da B3, e as empresas ali negociadas, devem estar registradas na Comissão de Valores Mobiliários (CVM) como capital aberto e informar ao mercado seus resultados a cada trimestre.

As ações são classificadas em basicamente dois tipos, ordinárias e preferenciais. As ordinárias são as que dão ao acionista o poder de participar das assembleias da empresa, podendo eleger e destituir os membros da diretoria e do conselho de determinada companhia. Já as preferenciais não atribuem ao investidor o direito de voto, porém dão outras preferências, como por exemplo:

- Prioridade do recebimento de dividendos, em caso de pagamento.

- Prioridade no reembolso de capital em uma eventual dissolução da empresa.

\subsection{Oferta Pública de Ações (IPO e Follow-on)}

Uma empresa pode se financiar mediante suas próprias atividades e recursos, retendo seus resultados líquidos e, principalmente, lançando ações ou debêntures ao público. No caso de ações, a negociação pode ocorrer de duas formas, a empresa emite novos papéis ou pela oferta pública das ações de um grande acionista, contudo, para que ocorra essa negociação, a empresa deve estar registrada na CVM como "Companhia Aberta". As debentures, devido ao cenário de juros baixos, estão menos atrativas para o investidor, mas costumam ocorrer quando a empresa precisa levantar recursos para financiar seus investimentos e o mercado demonstra maior disposição para receber juros como rendimentos (Assaf Neto, 2014).

Até abril de 2021, um total de 13 empresas abriram capital através de ações, movimentando um total de 20.854.000,00 e aproveitando o bom momento da bolsa, 
onde o investidor pessoa física vem buscando boas oportunidades em um momento de retomada após a crise do Coronavírus, no entanto, nenhuma delas ainda faz parte do ISE da B3.

Tabela 13: Empresas x performance desde o IPO

\begin{tabular}{|c|c|c|c|c|c|}
\hline Empresa & Data & $\begin{array}{c}\text { Tamanho da Oferta (R\$ } \\
\text { milhões) }\end{array}$ & Precificação da Oferta & Preço Atual* & Performance desde o IPO \\
\hline Espaço Laser & $01 / \mathrm{fev} / 21$ & $R \$ 2.642$ & 17,9 & 16 & $-12,63 \%$ \\
\hline Intelbras & $04 / \mathrm{fev} / 21$ & $\mathrm{R} \$ 1.304$ & 15,75 & 22,75 & $42,86 \%$ \\
\hline Mosaico & $05 / \mathrm{fev} / 21$ & $\mathrm{R} \$ 1.215$ & 19,8 & 21,72 & $14,55 \%$ \\
\hline Mobly & $05 / \mathrm{fev} / 21$ & $\mathrm{R} \$ 933$ & 21 & 19,9 & $-1,05 \%$ \\
\hline Jalles Machado & $08 / \mathrm{fev} / 21$ & $R \$ 738$ & 8,3 & 8,22 & $-0,36 \%$ \\
\hline Focus Energia & $08 / \mathrm{fev} / 21$ & $\mathrm{R} \$ 887$ & 18,02 & 13,87 & $-21,64 \%$ \\
\hline Bemobi & $10 / \mathrm{fev} / 21$ & $\mathrm{R} \$ 1.258$ & 22 & 20,96 & $-4,50 \%$ \\
\hline Cruzeiro do Sul & $11 / \mathrm{fev} / 21$ & $\mathrm{R} \$ 1.232$ & 14 & 12,2 & $-15,21 \%$ \\
\hline Westwing & $11 / \mathrm{fev} / 21$ & $\mathrm{R} \$ 1.162$ & 13 & 8,46 & $-32,77 \%$ \\
\hline Oceanpact & $12 / \mathrm{fev} / 21$ & $\mathrm{R} \$ 1.220$ & 11,15 & 8,65 & $-19,37 \%$ \\
\hline Orizon & $17 /$ fev/21 & $\mathrm{R} \$ 554$ & 22 & 21,47 & $-4,09 \%$ \\
\hline Eletromídia & $17 / \mathrm{fev} / 21$ & $\mathrm{R} \$ 872$ & 17,81 & 17,71 & $-0,22 \%$ \\
\hline CSN Mineração & $18 / \mathrm{fev} / 21$ & $R \$ 5.219$ & 8,5 & 9,57 & $14,35 \%$ \\
\hline Mater Dei & $16 / a b r / 21$ & $\mathrm{R} \$ 1.618$ & 17,44 & 16,8 & $-7,17 \%$ \\
\hline Total & & $\mathrm{R} \$ 20.854$ & & Data Base: 19/04/21 & \\
\hline
\end{tabular}

Fonte: Dados retirados do site da XP Investimentos e cotações do programa XP

PRO - Abril 2021

A abertura de capital é justificada, principalmente, pela intenção das empresas em financiar novos projetos de investimentos, promover o crescimento e a modernização de suas atividades.

As empresas que já possuem sua negociação listada na bolsa de valores também podem captar recursos através de uma oferta de ações através de um processo chamada follow-on. 


\section{Pesquisa}

Esse capítulo tem como objetivo descrever os procedimentos de coleta e análise dos dados. O capítulo está dividido na descrição dos procedimentos de coleta de dados, posteriormente nos métodos de análise e concluindo a seção com as limitações do estudo.

O estudo classifica-se como uma pesquisa quantitativa, tendo como objetivo comparar a rentabilidade de determinados produtos financeiro que utilizam o tema ESG na composição de sua carteira de investimentos com investimentos tradicionais no Brasil, no período de 2019 até abril e maio de 2021.

\subsection{Procedimento de Coleta dos Dados}

Na primeira etapa, foi pesquisado uma gestora de recursos que possui em seu portfólio fundos de investimentos majoritariamente classificados como ESG, a partir disso, um desses fundos foi escolhido. Junto a isso, foi selecionada outra gestora de recursos independente, porém, que não possui nenhum tipo de política de gestão ESG. Além disso, foram escolhidos outros dois fundos geridos por dois grandes bancos brasileiros, sendo um deles classificado como ESG e outro não.

Após feita essa seleção, a monografia apresenta a rentabilidade do índice ISE da B3, do Ibovespa e do CDI no mesmo período em que os fundos foram analisados, analisando qual desses indicadores gerou mais retorno. Todos os dados foram retirados da plataforma Quantum Axis e do próprio site da B3.

$\mathrm{Na}$ terceira etapa, com os fundos escolhidos, apresento e comparo a rentabilidade absoluta, relativa em relação ao CDI, ao Ibovespa e ao ISE, o Sharpe, Treynor, Sortino e o Drawdown de cada fundo. Para obter a rentabilidade e métricas de cada um dos fundos e indicadores foi utilizada novamente a plataforma Quantum Axis. 


\subsection{Métodos de análises dos dados}

A rentabilidade passada dos fundos e índices foram buscadas no Quantum Axis e passadas para Excel, a fim de tratar e formatar os dados com mais facilidade através de fórmulas e recursos do programa. Os gráficos apresentados foram feitos pelo próprio Excel, após inserir os dados apresentados no Quantum manualmente no sistema.

Assim, é possível obter a rentabilidade passada, calcular as métricas que foram utilizadas e fazer as comparações dos fundos entre si e com os índices apresentados, o ISE e Ibovespa.

\subsection{Limitações do Estudo}

Uma das limitações do estudo é o curto período em que os fundos de investimentos brasileiros utilizam o conceito de ESG na montagem de seus respectivos portfólios e a recém criação de investimentos voltados integralmente para o tema. O tema já é debatido há anos em países com mercado financeiro mais desenvolvido, contudo, no Brasil ainda é recente.

Outra limitação é em relação a carteira de investimentos dos fundos analisados, não é possível obter exatamente todos os ativos que compõe cada carteira, contudo, por questão de ética, sendo o fundo classificado como ESG, grande parte do portfólio respeita os conceitos necessários. Porém, é possível que algumas empresas contidas na carteira não façam parte do ISE, mas na visão do gestor, pode ser considerada como sustentável.

Além disso, vale ressaltar que o estudo não é capaz de analisar a qualidade de cada gestão, são apresentadas a rentabilidade e os indicadores quantitativos passados de cada produto e com base nisso são feitas as comparações e respectivas análises. Sendo importante ressaltar que a rentabilidade passada desses fundos não é garantia de que a performance será a mesma nos próximos anos, podendo essa variar para melhor ou pior. 


\section{Apresentação e análise dos resultados \\ 4.1 Seleção das Gestoras de Recursos e Fundos}

Primeiramente foram selecionadas quatro gestoras de investimentos, sendo essas: Constellation Asset Management, Bahia Asset Management, Bradesco Asset Management e Santander Asset Management, sendo as duas primeiras gestoras independentes e outras duas pertencentes a grandes bancos brasileiros.

\section{Constellation Asset Management}

A Constellation é atualmente a gestora de recursos brasileira mais engajada em incorporar fatores ambientais, sociais e de governança (ESG) nos fundos de investimento e dentro do mercado financeiro brasileiro acreditam ser um dos segmentos com mais possibilidade de crescimento.

Conforme histórico apresentado no site da empresa, com mais de vinte anos de história no mercado financeiro, em 1998 o sócio fundador, Florian Bartunek, foi convidado por ex-sócios do Banco Garantia, um dos pioneiros no mercado brasileiro, para gerir os investimentos deles em 2002, em parceira com Jorge Paulo Lemann. Assim, nasceu a Constellation, com 64 milhões de reais sob gestão. Em 2005, foi lançado o primeiro fundo Long Only da gestora, que possui como estratégia estar sempre com 67\% do portfólio comprado em ações e em 2013 a gestora encerrou o ano com 2,4 bilhões de reais sob gestão.

Em 2019, ocorreu um dos maiores marcos da Constellation, ela se tornou signatária do PRI (Principles for Responsible Investment) e atingiu 9 bilhões de reais sob gestão, atingindo investidores institucionais do mundo inteiro e individuais. Em 2020, a operação encerrou o ano com 16 bilhões sob gestão.

Em agosto de 2018, pouco antes de se tornar signatária do PRI, foi lançado o produto Constellation Compounders ESG FIC FIA, fundo que tem como objetivo obter retornos superiores através de investimentos a longo prazo em empresas brasileiras listadas em bolsa e que possuem retornos altos, consistentes e sustentáveis, cujos valores de suas ações tendem a acompanhar o crescimento de lucros. 


\section{Bahia Asset Management}

Segundo apresentado no site da gestora, a Bahia Asset é uma gestora de recursos independente, uma das mais tradicionais no segmento dentro do Brasil e é focada exclusivamente na gestão de recursos de terceiros com foco no médio e longo prazo.

Atualmente, a asset é composta por duas gestoras dentro de sua estrutura: a Bahia AM Renda Variável e Bahia AM Renda Fixa, possui mais de 17 bilhões de reais sob gestão e 95 colaboradores.

Dentro do portfólio de investimentos, a empresa ainda não possui nenhum tipo de estratégia focada no conceito ESG e para realizar a comparação e análise, foi escolhido o fundo BAHIA AM VALUATION FI AÇÕES.

\section{Bradesco Asset Management}

Conforme especificado no site do banco, fundada em 2001, a Bradesco Asset Management é uma das maiores gestoras privadas do país e possui mais de 520 bilhões de reais sob gestão, mais de 200 profissionais e uma grade completa de fundos no portfólio. Ela serve como auxílio de um dos maiores bancos privados do Brasil, o Bradesco, que administra mais de 1,6 trilhão de reais e mais de 70 milhões de clientes espalhados pelo país.

Em 2019, a equipe revisou a estratégia de sustentabilidade considerando os conceitos ESG e observando os desafios e tendencias globais, foram lançados os primeiros produtos sustentáveis do banco e diversas ações sociais passaram a ser praticadas pelo banco, com mais de 14 milhões doados para projetos apoiados pelo Fundo Municipal da Criança e do Adolescente (Fumcad) e para projetos que asseguram os direitos sociais do idoso.

No cenário nacional, o Bradesco é o banco privado brasileiro com a melhor posição no Índice de Sustentabilidade Dow Jones e já possui 100\% das operações abastecidas por energias renováveis e são carbono neutro, ou seja, compensam as emissões com outros projetos sustentáveis. Ao longo da crise da pandemia de COVID-19 em 2020 e 2021, o banco protagonizou diversas ações beneficentes para ajudar no combate da pandemia, como a importação de 5 milhões de testes rápidos, 
doação de 15 milhões de máscaras e 150 mil cestas básicas doadas para comunidades carentes.

O Bradesco FIA Sustentabilidade Empresarial é um produto lançado em 2007, Long Only Livre e desde 2019 com foco em empresas brasileiras com boa avaliação ESG, a equipe de gestão é liderada pelo gestor Milton Cabral e conta com outros seis analistas e um analista focado especialmente em ESG.

\section{Santander Asset Management}

Segundo site da gestora, a Santander Asset é uma das maiores assets globais, presente em onze países e com patrimônio sob gestão no Brasil de 290 bilhões de reais, atuando há mais de trinta anos no Brasil, a gestora oferece diversos produtos de investimentos e possui mais de 710 mil clientes.

O fundo escolhido para análise é o SELEÇÃO CRESCIMENTO AÇÕES FIC FIA, fundo que investe em ações e que não possui nenhum tipo de prática ESG adotada na montagem de seu portfólio.

\subsection{Rentabilidade dos Ativos}

\subsection{1 Índice ISE x Índice lbovespa}

No gráfico e tabelas abaixo é possível analisar a rentabilidade absoluta dos índices Ibovespa e do Índice de Sustentabilidade Empresarial da B3, o ISE, sendo possível identificar que desde 2019, o Ibovespa teve uma rentabilidade absoluta superior ao que se limita as empresas que seguem os padrões ESG. 
Tabela 14: Rentabilidade absoluta dos índices Ibovespa e do Índice de Sustentabilidade Empresarial da B3

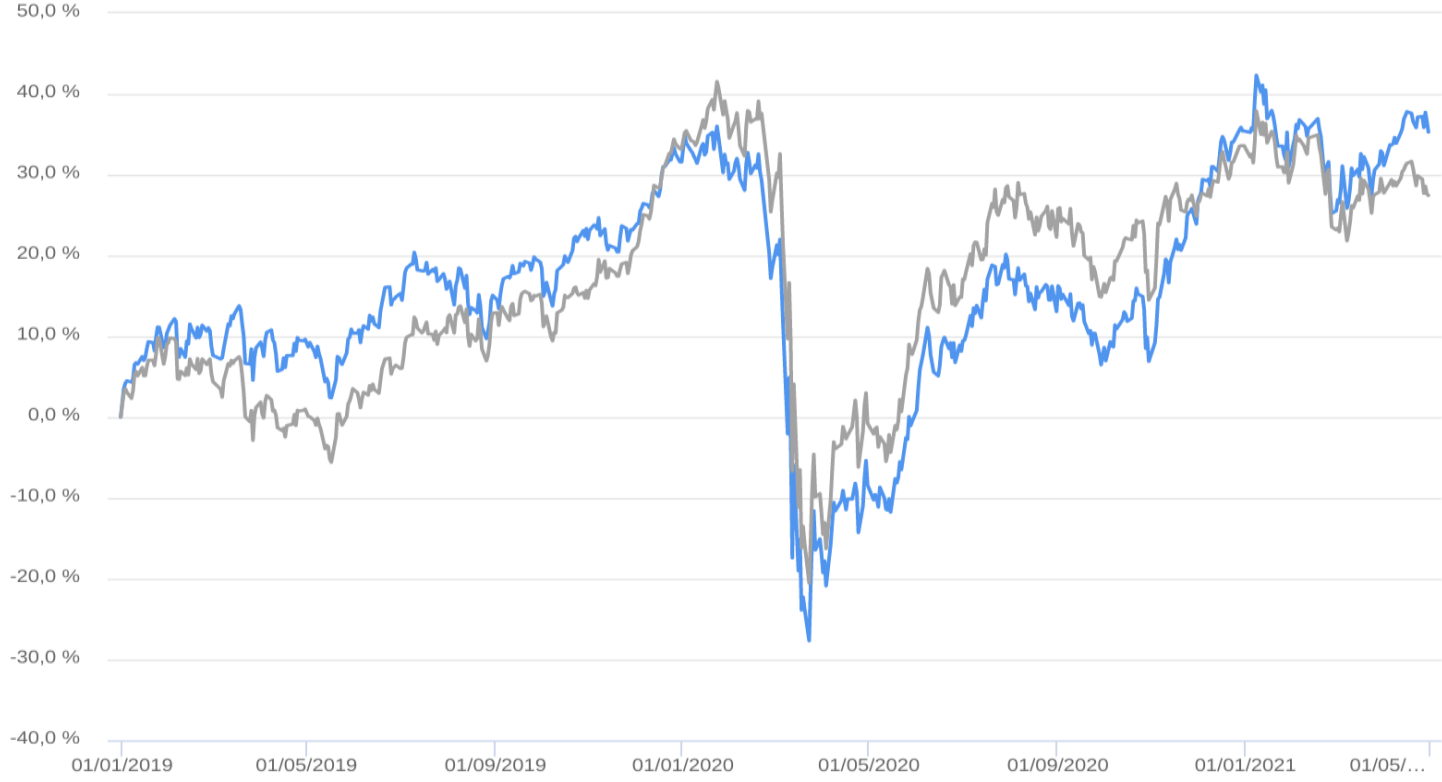

Fonte: Elaboração própria a partir de dados disponibilizados pelo Quantum Axis (2021)

Tabela 15: Retorno acumulado 1/1/2019 a 30/4/2021

$\begin{array}{lcccc}\text { Indice } & \mathrm{abr} / 21 & \mathrm{mar} / 21 & \mathrm{fev} / 21 & \mathrm{jan} / 21 \\ \text { ISE } & -0,95 & 4,14 & -4,21 & -3,45 \\ \text { Ibovespa } & 1,94 & 6 & -4,37 & -3,32\end{array}$

Índice dez/20 nov/20 out/20 set/20 ago/20 jul/20 jun/20 mai/20 abr/20 mar/20 fev/20 jan/20

$\begin{array}{lcccccccccccc}\text { ISE } & 7,01 & 9,04 & -0,99 & -5,42 & -3,94 & 10,84 & 6,55 & 8,61 & 12,61 & -30,51 & -5,75 & 1,01 \\ \text { Ibovespa } & 9,3 & 15,9 & -0,69 & -4,8 & -3,44 & 8,27 & 8,76 & 8,57 & 10,25 & -29,9 & -8,43 & -1,63\end{array}$

Índice dez/19 nov/19 out/19 set/19 ago/19 jul/19 jun/19 mai/19 abr/19 mar/19 fev/19 jan/19

$\begin{array}{lcccccccccccc}\text { ISE } & 10,44 & 5,13 & -0,42 & 2,04 & 2,21 & 3,78 & 2,82 & 2,5 & -0,19 & -3,94 & -3,53 & 9,19 \\ \text { Ibovespa } & 6,85 & 0,95 & 2,36 & 3,57 & -0,67 & 0,84 & 4,06 & 0,7 & 0,98 & -0,18 & -1,86 & 10,82\end{array}$

Fonte: Elaboração própria através de dados retirados no Quantum Axis

Na elaboração do gráfico foram considerados todos os dias de negociação dos ativos até o final de abril de 2021 e nas tabelas acima, a variação mensal. Grande 
parte das vezes, quando um deles apresentou rentabilidade negativa no mês, o outro teve o mesmo comportamento ou teve rentabilidade levemente positiva, logo, há uma correlação forte entre os dois índices.

Contudo, é possível notar que o ISE teve uma performance inferior ao Ibovespa no período analisado, tendo uma rentabilidade absoluta de $27,45 \%$ contra $35,28 \%$ do índice tradicional.

Tal fato ocorre, em grande parte, porque o Ibovespa é uma carteira mais diversificada do que o ISE, contando com mais ativos no portfólio, o que mitiga os riscos de mercado, principalmente o sistemático. Importante ressaltar que após a pandemia, é evidente no gráfico que as empresas sustentáveis tiveram uma recuperação mais acelerada em seus valores de mercado.

Atualmente, para acompanhar a rentabilidade dos dois índices, o investidor pode comprar dois ETFs que possuem na carteira os ativos de cada um, são esses BOVA11 (Ibovespa) e ISUS11 (ISE).

\subsubsection{Constellation Compounders $x$ Bahia AM Valuation FIC AÇÕES}

Tabela 16: Constellation Compounders x Bahia AM Valuation FIC AÇÕES

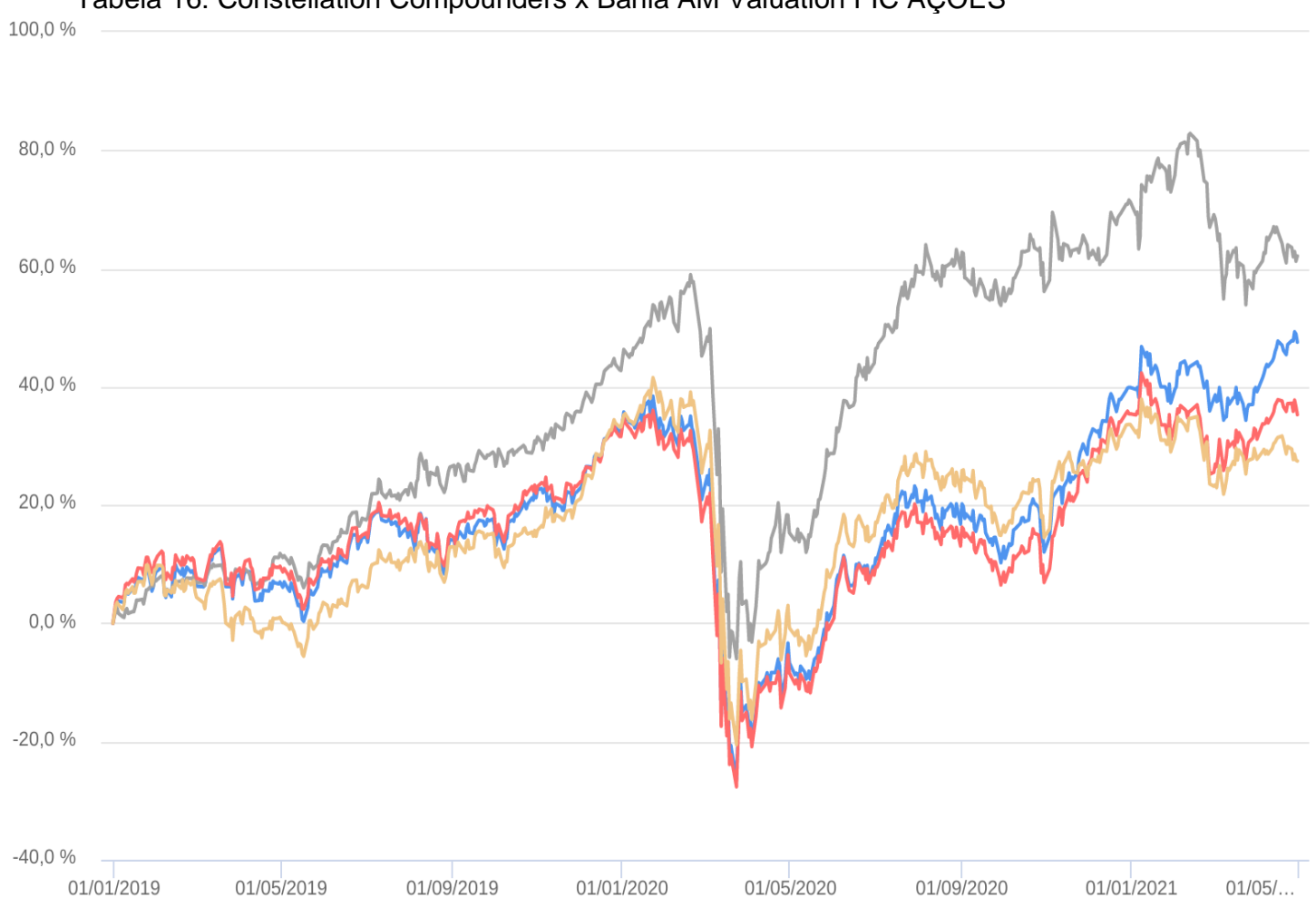

Fonte: Elaboração própria a partir de dados disponibilizados pelo Quantum Axis 
Tabela 17: Retorno acumulado 1/1/2019 a 30/4/2021

$\begin{gathered}\text { Retorno acumulado - 01/01/2019 até 30/04/2021 (diária) } \\ \text { Ativo }\end{gathered}$
$\begin{array}{lc}\text { Retorno } \\ \text { BAHIA AM VALUATION FIC AÇÕES } & 47,54 \% \\ \text { CONSTELLATION COMPOUNDERS ESG FIC A } & 62,11 \% \\ \text { Ibovespa } & 35,28 \% \\ \text { ISE } & 27,45 \%\end{array}$

\begin{tabular}{lccccc} 
Fundo / Índice & $\mathrm{abr} / \mathbf{2 1}$ & $\mathrm{mar} / \mathbf{2 1}$ & $\mathbf{f e v} / \mathbf{2 1}$ & $\mathbf{j a n} / \mathbf{2 1}$ & $\mathbf{2 0 2 1}$ \\
\hline BAHIA AM & 5,48 & 2,91 & $-0,97$ & $-1,88$ & 5,48 \\
CONSTELLATION & 1,76 & $-4,59$ & $-3,46$ & 0,99 & $-5,34$ \\
Ibovespa & 1,94 & 6 & $-4,37$ & $-3,32$ & $-0,1$ \\
ISE & $-0,95$ & 4,14 & $-4,21$ & $-3,45$ & $-4,61$
\end{tabular}

\begin{tabular}{|c|c|c|c|c|c|c|c|c|c|c|c|c|c|}
\hline & & & & & & & & & & & & & 2020 \\
\hline BAHIA AM & 8,8 & 14,74 & 0,43 & $-4,45$ & $-3,12$ & 10,35 & 8,04 & 8,34 & 10,36 & $-30,69$ & $-7,29$ & $-0,58$ & $5,70 \%$ \\
\hline CONSTELLATION & 4,47 & 4,99 & 0,51 & $-2,92$ & 0,34 & 10,75 & 11,88 & 11,62 & 13,63 & $-30,41$ & $-3,83$ & 6,2 & $19,96 \%$ \\
\hline Ibovespa & 9,3 & 15,9 & $-0,69$ & $-4,8$ & $-3,44$ & 8,27 & 8,76 & 8,57 & 10,25 & $-29,9$ & $-8,43$ & $-1,63$ & $2,92 \%$ \\
\hline SE & 7,01 & 9,04 & $-0,99$ & $-5,42$ & $-3,94$ & 10,84 & 6,55 & 8,61 & 12,61 & $-30,51$ & $-5,75$ & 1,01 & $0,32 \%$ \\
\hline
\end{tabular}

\begin{tabular}{|c|c|c|c|c|c|c|c|c|c|c|c|c|c|}
\hline div & /19 & $v / 19$ & t/19 & /19 & $0 / 19$ & /19 & n/19 & ai/19 & br/19 & ar/19 & fev/19 & jan/19 & \\
\hline BAHIA AM & 8,34 & 0,76 & 3,07 & 3,06 & $-0,37$ & 0 & 5,34 & 1,67 & $-0,74$ & 0,52 & $-1,4$ & 8,71 & $32,33 \%$ \\
\hline CONSTELLATION & 5,1 & 4,09 & 1,2 & 2,02 & 3,84 & 3,39 & 4 & 1,27 & 2,45 & 1,5 & 0,31 & 7,18 & $42,76 \%$ \\
\hline Ibovespa & 6,85 & 0,95 & 2,36 & 3,57 & $-0,67$ & 0,84 & 4,06 & 0,7 & 0,98 & $-0,18$ & $-1,86$ & 10,82 & $31,58 \%$ \\
\hline ISE & 10,44 & 5,13 & $-0,42$ & 2,04 & 2,21 & 3,78 & 2,82 & 2,5 & $-0,19$ & $-3,94$ & $-3,53$ & 9,19 & $33,19 \%$ \\
\hline
\end{tabular}

Fonte: Elaboração própria a partir de dados disponibilizados pelo Quantum Axis

(2021)

Observando a rentabilidade, o Constellation foi bem superior ao Bahia em 2019 e 2020. Em 2019 o fundo obteve $42,76 \%$ de rentabilidade, enquanto o Bahia teve $32,33 \%$ no mesmo período. Os dois fundos tiveram retorno superiores ao Ibovespa e somente o Constellation conseguiu se sair melhor do que o ISE. Já em 2020, ano da pandemia, o fundo ESG teve um retorno de 19,96\% de rentabilidade contra 5,70\% do Bahia, os dois produtos se saíram melhores do que os índices em questão. Em 2021, até o final de abril, o Bahia se saiu superior, o fundo gerou uma 
rentabilidade positiva de 5,48\% contra o Constellation que não apresentou um retorno positivo no período.

Sharpe:

Tabela 18: Sharpe

\begin{tabular}{|c|c|c|c|}
\hline \multicolumn{2}{|c|}{ Sharpe - 22/05/2019 até 21/05/2021 } \\
\hline Nome & Volatilidade & $\begin{array}{c}\text { Retorno } \\
\text { Anualizado }\end{array}$ & Sharpe - CDI \\
\hline BAHIA AM & $33,67 \%$ & $18,11 \%$ & $\mathbf{0 , 4 3}$ \\
\hline CONSTELLATION COMPOUNDERS & $30,71 \%$ & $20,86 \%$ & $\mathbf{0 , 5 6}$ \\
\hline CDI & $0,10 \%$ & $3,58 \%$ & $\mathbf{0}$ \\
\hline Ibovespa & $33,86 \%$ & $13,91 \%$ & $\mathbf{0 , 3 1}$ \\
\hline ISE & $32,68 \%$ & $14,35 \%$ & $\mathbf{0 , 3 3}$ \\
\hline
\end{tabular}

Fonte: Elaboração própria a partir de dados disponibilizados pelo Quantum Axis (2021)

No cálculo dos índices de Sharpe, Treynor e Sortino, foi utilizado um período de 24 meses corridos, levando em consideração o período de 21/05/2019 até $21 / 05 / 2021$.

Foi utilizada a fórmula:

$\mathrm{IS}=(\mathrm{Ri}-\mathrm{Rf}) /(\sigma \mathrm{i})$

Sendo Ri o retorno do ativo analisado, Rf o retorno livre de risco (CDI) e o desvio padrão é o risco do ativo (Volatilidade).

Bahia AM: IS $=(0,1811-0,0358) /(0,3367)->$ IS $=0,43$

Constellation Compounders: IS $=(0,2086-0,0358) /(0,3071)->$ IS $=0,56$

Com isso, levando em consideração o conceito do índice de Sharpe, a cada $1 \%$ de risco embutido nas operações feitas por cada um dos fundos, o Bahia gerou $0,43 \%$ de prêmio acima do que foi gerado pelo ative livre de risco (CDI) no período analisado.

Já o Constellation, a cada 1 ponto de nível de risco, o fundo gerou 0,56 pontos de retorno a mais, número superior ao apresentado pelo Bahia, principalmente pelo fato de ambos terem volatilidade semelhante. 
Com base na relação de risco e retorno pelo índice de Sharpe, o fundo da Constellation, que possui um mandato de investir apenas em empresas ESG, apresenta um quociente mais alto do que o Bahia AM, portanto, o produto sustentável foi mais eficiente no período, pagando ao investidor uma remuneração maior (prêmio de risco) por unidade de risco assumido.

Drawdown:

Tabela 19: Drawdown

\begin{tabular}{lrrrrr}
\multicolumn{1}{c}{ Ativo } & \multicolumn{2}{c}{$\begin{array}{l}\text { Drawdown - 22/05/2019 à 21/05/2021 (diária) } \\
\text { Retorno }\end{array}$} & $\begin{array}{c}\text { Volatilidade } \\
\text { Início do Máximo } \\
\text { Drawdown }\end{array}$ & $\begin{array}{c}\text { Data do Máximo } \\
\text { Drawdown }\end{array}$ & $\begin{array}{c}\text { Máximo } \\
\text { Drawdown }\end{array}$ \\
BAHIA AM & $39,51 \%$ & $33,67 \%$ & $23 / 01 / 2020$ & $23 / 03 / 2020$ & $-46,77 \%$ \\
CONSTELLATION & $46,08 \%$ & $30,71 \%$ & $19 / 02 / 2020$ & $23 / 03 / 2020$ & $-40,86 \%$ \\
CDI & $7,28 \%$ & $0,10 \%$ & & & \\
Ibovespa & $29,75 \%$ & $33,86 \%$ & $23 / 01 / 2020$ & $23 / 03 / 2020$ & $-46,82 \%$ \\
ISE & $30,75 \%$ & $32,68 \%$ & $23 / 01 / 2020$ & $23 / 03 / 2020$ & $-43,86 \%$
\end{tabular}

Fonte: Elaboração própria a partir de dados disponibilizados pelo Quantum Axis (2021)

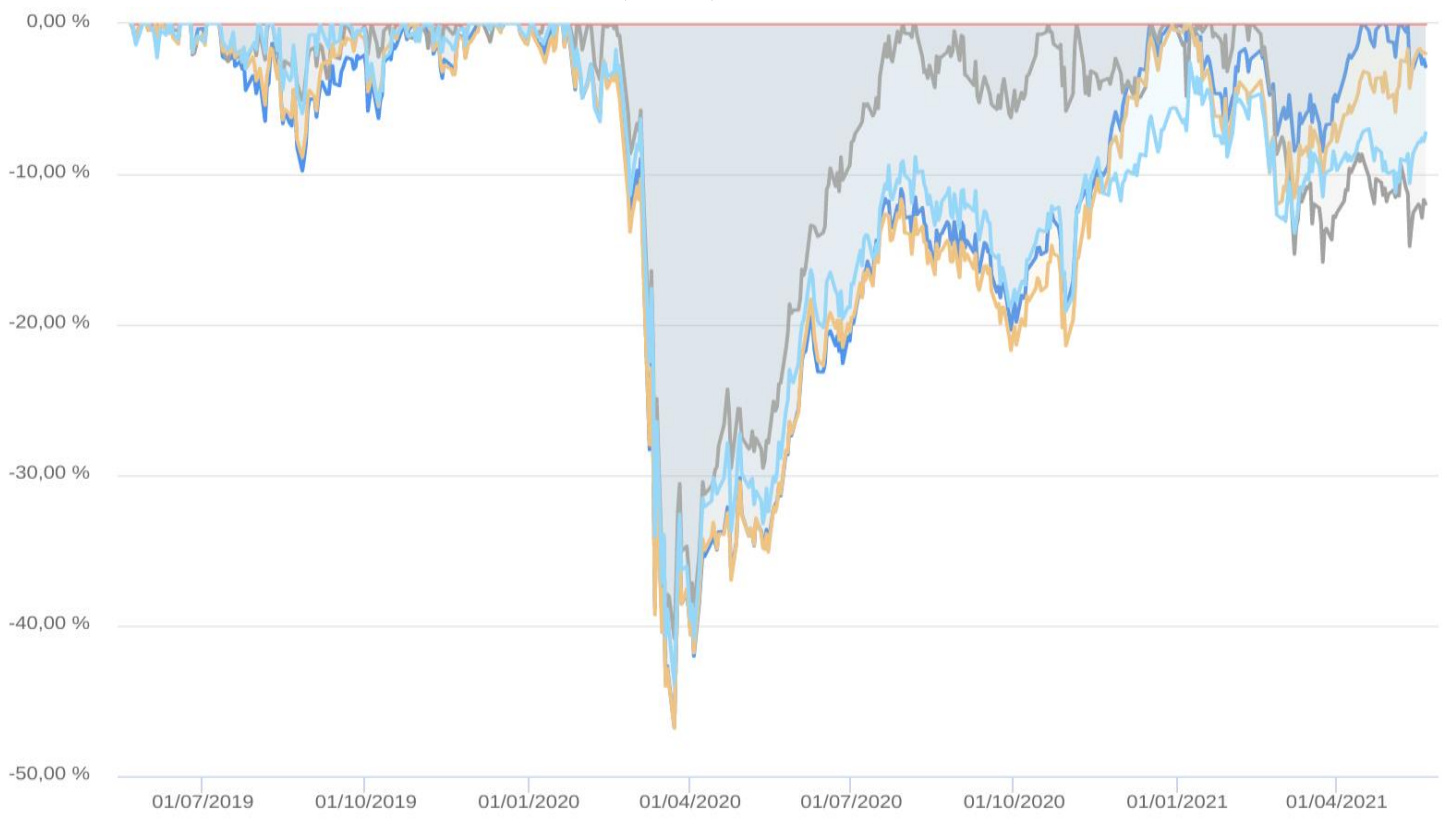

Se tratando de drawdown, 2020 foi um ano atípico para o mercado financeiro mundial, graças a uma das maiores crises financeiras que vem acontecendo e isso se refletiu nas performances dos fundos de investimento.

Desde janeiro de 2020, patamar que a bolsa estava próxima dos $120 \mathrm{mil}$ pontos e os fundos vivenciavam suas melhores rentabilidades em anos, a crise 
sanitária decorrente do Coronavírus começou a apresentar sinais na China e não demorou para que chegasse ao Brasil.

A partir do dia 23/01, data do maior valor de cota do Bahia AM Valuation, começou o drawdown do fundo, que chegou a atingir $46,77 \%$ de queda no dia 23/03/2021, dia histórico para a bolsa brasileira e que marcou o acontecimento de três circuit-breaks em um mesmo pregão.

O Constellation demorou um pouco mais para iniciar o drawdown, que começou no dia 19/02 e teve como pior cenário uma queda de -40,86\% também no dia 23/03.

Com esses dados, ainda que os dois fundam tenham passado por quedas muito elevadas e além do nível de volatilidade estipulado, o Constellation se saiu melhor na crise e apresentou uma recuperação mais rápida do que o Bahia, indicando que as empresas dentro do portfólio, sendo todas ESG, tiveram um desempenho e seu valor de mercado recuperado mais rapidamente.

Treynor:

Tabela 20: Treynor

\begin{tabular}{|c|c|c|c|c|}
\hline \multirow[b]{2}{*}{ Nome } & \multicolumn{4}{|c|}{$22 / 05 / 2019$ até $21 / 05 / 2021$} \\
\hline & Retorno Médio & $\begin{array}{c}\text { Beta - } \\
\text { CDI/Ibovespa } \\
\text { diária }\end{array}$ & $\begin{array}{l}\text { Beta - } \\
\text { CDI/ISE }\end{array}$ & $\begin{array}{l}\text { Treynor - } \\
\text { CDI/Ibovespa }\end{array}$ \\
\hline BAHIA AM VALUATION FIC AÇÕES & $0,09 \%$ & 0,98 & 0,98 & 0,193383825 \\
\hline CONSTELLATION COMPOUNDERS ESG FIC AÇÕES & $0,09 \%$ & 0,81 & 0,87 & 0,233456955 \\
\hline CDI & $0,01 \%$ & 0 & 0 & \\
\hline Ibovespa & $0,07 \%$ & 1 & 1 & 0,15 \\
\hline ISE & $0,07 \%$ & 0,93 & 1 & 0,17 \\
\hline
\end{tabular}

Fonte: Elaboração própria a partir de dados disponibilizados pelo Quantum Axis

(2021)

Para calcular o Treynor de cada um dos fundos, foi utilizado o retorno médio diário de cada um dos indicadores no período, o benchmark escolhido foi o Ibovespa e o ativo livre de risco o CDI.

$$
\mathrm{IT}=(\mathrm{Ra}-\mathrm{Rf}) /(\mathrm{Ba})
$$


Bahia AM: IT $=(0,09 \%-0,01 \%) / 0,98=0,000767396$

Constellation: $\mathrm{IT}=(0,09 \%-0,01 \%) / 0,81=0,000926$

Com o Treynor diário calculado, utilizou-se o período de 252 dias para chegar no valor do indicador ao ano.

Assim, chegamos nos valores 0,193383825 (19,33\%) para o Bahia AM e $0,233456955(23,34 \%)$ para o Constellation.

Quanto mais alto o índice de Treynor, maior é o retorno da carteira por unidade de risco assumido e, diferente do Sharpe, a estrutura de risco assumida se relaciona ao prêmio unicamente com a medida de risco sistemático (Beta), enquanto o Sharpe adota o desvio padrão (risco total: sistemático e não sistemático), para carteiras de fundos bem diversificadas, os dois índices apontam para a mesma conclusão.

Logo, ao calcular o indicador dos fundos, identificamos que o Constellation, além de apresentar uma rentabilidade maior no período, demonstrou mais eficiência do que o Bahia, o fundo teve uma eficiência de $23,34 \%$ com o risco sistêmico considerado no período.

Sortino:

Tabela 21: Sortino
\begin{tabular}{|c|c|c|c|c|c|}
\hline & \multicolumn{5}{|c|}{$\mathbf{2 2 / 0 5 / 2 0 1 9}$ até 21/05/2021 } \\
\hline Nome & $\begin{array}{c}\text { Retorno } \\
\text { Médio } \\
\text { Diario }\end{array}$ & $\begin{array}{c}\text { Downsid } \\
\text { e Risk - } \\
\text { CDI }\end{array}$ & $\begin{array}{c}\text { Retorno } \\
\text { Excedente }\end{array}$ & $\begin{array}{c}\text { Sortino - } \\
\text { Diaria }\end{array}$ & $\begin{array}{c}\text { Sortino - } \\
\text { CDI }\end{array}$ \\
\hline BAHIA & $0,09 \%$ & 0,01601 & 0,00075 & 0,046884 & $\mathbf{0 , 7 4 2 2 4}$ \\
CONSTELLATION & $0,09 \%$ & 0,01487 & 0,0008 & 0,054061 & $\mathbf{0 , 8 5 8 2 8 7}$ \\
\hline Ibovespa & $0,07 \%$ & 0,01611 & 0,00061 & 0,037805 & $\mathbf{0 , 6 0 0 1 5 5}$ \\
\hline ISE & $0,07 \%$ & 0,0157 & 0,00061 & 0,038781 & $\mathbf{0 , 6 1 5 6 7 5}$ \\
\hline
\end{tabular}

Fonte: Elaboração própria a partir de dados disponibilizados pelo Quantum Axis

(2021)

O índice de Sortino, como uma adaptação do Sharpe, também tem como função principal medir o risco e retorno de um fundo, contudo, enquanto o Sharpe considera as oscilações positivas e negativas, o Sortino considera somente os retornos negativos de um portfólio no período. 
Acima, segue o resultado do cálculo do índice de Sortino dos fundos independentes, e para chegarmos no resultado, utilizamos a medidas acima e o ativo livre de risco foi o CDI, que apresentou um retorno médio diário de 0,0139\%.

$\mathrm{Is}=((\mathrm{Ri}-\mathrm{Rf}) /(\sigma$ dos retornos negativos $)) *\left((252)^{\wedge}(1 / 2)\right)$

Bahia: Isa $=(0,890 \%-0,0139 \%) / 1,6006 \%=4,6884 \% *((252) \wedge(1 / 2))=$ $74,4224 \%$ a.a

Constellation: Isa $=(0,0944 \%-0,0139 \%) /(1,6006 \%+=5,4061 \% *((252)$ $\wedge(1 / 2))=\mathbf{8 5}, \mathbf{8 2 8 7} \%$ a.a

Sendo superior no índice se Sortino, o Constellation, mais uma vez, demonstrou que um portfólio ESG tem capacidade de superar um fundo tradicional do mercado, e ter um Sortino mais alto, demonstra a capacidade do fundo em se proteger melhor em momento de queda do mercado.

\subsubsection{Bradesco FIA Sustentabilidade Empresarial $x$ SANTANDER SELEÇÃO CRESCIMENTO FIC AÇÕES}

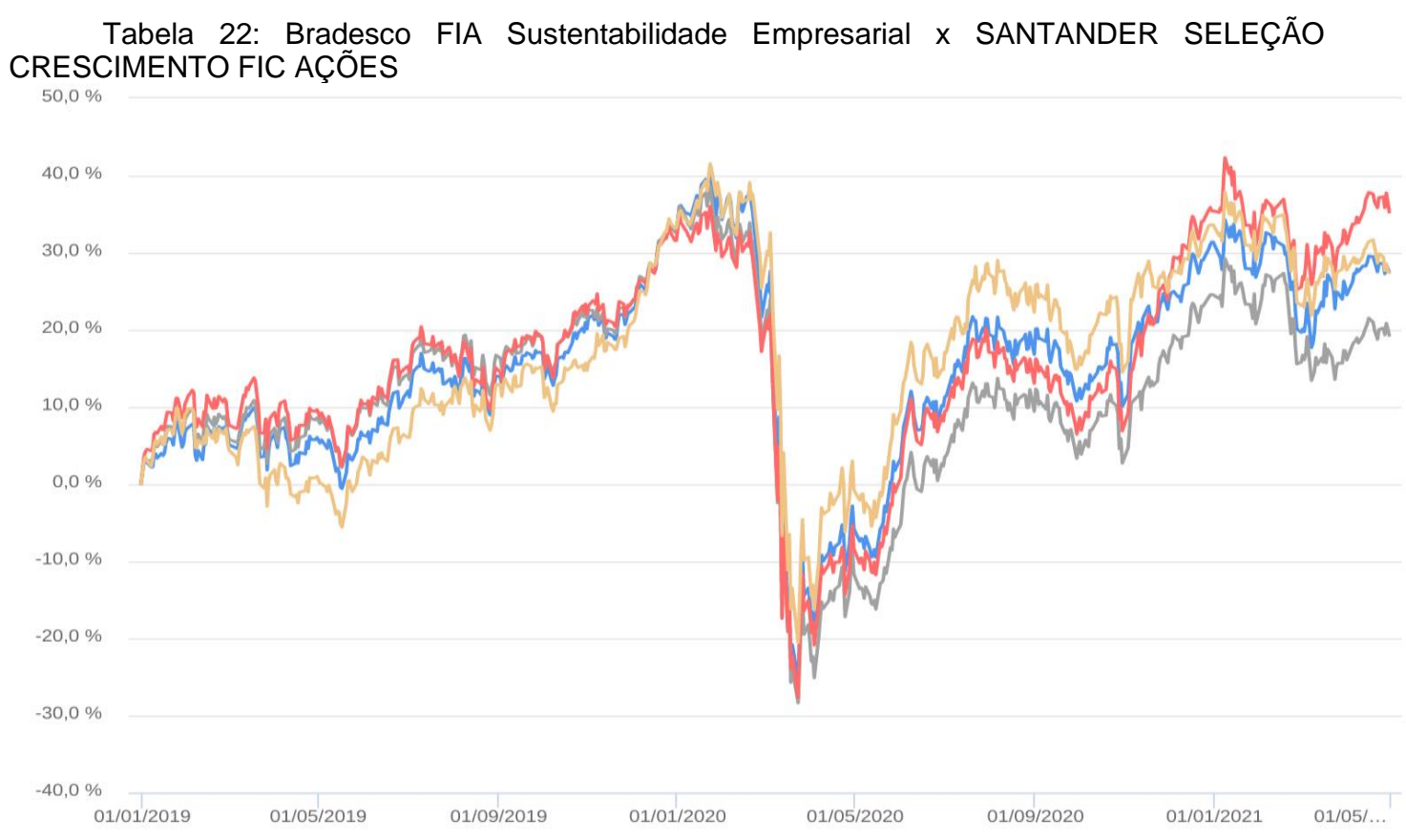


Fonte: Elaboração própria a partir de dados disponibilizados pelo Quantum Axis

\begin{tabular}{|c|c|}
\hline $\begin{array}{c}\text { Retorno acumulado - } 01 / 0 \\
\text { Ativo }\end{array}$ & $\begin{array}{l}\text { (diária) } \\
\text { Retorno }\end{array}$ \\
\hline BRADESCO SUSTENTABILIDADE EMPRESARIAL FI AÇÕES & $27,46 \%$ \\
\hline SANTANDER SELEÇÃO CRESCIMENTO FIC AÇÕES & $19,28 \%$ \\
\hline Ibovespa & $35,28 \%$ \\
\hline ISE & $27,45 \%$ \\
\hline
\end{tabular}

Tabela 23: retorno acumulado 1/1/2019 a 30/4/2021

\begin{tabular}{cccccc|} 
Nome & abr/21 & mar/21 & fev/21 & jan/21 & $\mathbf{2 0 2 1}$ \\
\hline BRADESCO & 1,45 & 4,61 & $-5,29$ & $-3,48$ & $-2,98 \%$ \\
SANTANDER & 1,69 & 1,48 & $-4,29$ & $-3,03$ & $-4,22 \%$ \\
ISE & $-0,95$ & 4,14 & $-4,21$ & $-3,45$ & $-0,10 \%$ \\
Ibovespa & 1,94 & 6 & $-4,37$ & $-3,32$ & $-4,61 \%$
\end{tabular}

$\begin{array}{cccccccccccccc}\text { Nome } & \text { dez/20 } & \text { nov/20 } & \text { out/20 } & \text { set/20 } & \mathbf{4 4 0 4 4} & \text { jul/20 } & \text { jun/20 } & \text { mai/20 } & \text { abr/20 } & \text { mar/20 } & \text { fev/20 } & \text { jan/20 } & 2020 \\ \text { BRADESCO } & 7,13 & 11,4 & -1,45 & -4,37 & -2,19 & 8,49 & 7,67 & 8,53 & 11,21 & -30,94 & -8,65 & 1,14 & -1,04 \% \\ \text { SANTANDER } & 7,62 & 12,65 & -1,95 & -4,27 & -1,81 & 8,91 & 9,31 & 6,02 & 10,93 & -33,44 & -9,2 & -0,7 & -6,12 \% \\ \text { ISE } & 7,01 & 9,04 & -0,99 & -5,42 & -3,94 & 10,84 & 6,55 & 8,61 & 12,61 & -30,51 & -5,75 & 1,01 & 2,92 \% \\ \text { Ibovespa } & 9,3 & 15,9 & -0,69 & -4,8 & -3,44 & 8,27 & 8,76 & 8,57 & 10,25 & -29,9 & -8,43 & -1,63 & 0,32 \%\end{array}$

$\begin{array}{cccccccccccccc}\text { Nome } & \text { dez/19 } & \text { nov/19 } & \text { out/19 } & \text { set/19 } & \mathbf{4 3 6 7 8} & \text { jul/19 } & \text { jun/19 } & \text { mai/19 } & \text { abr/19 } & \text { mar/19 } & \text { fev/19 } & \text { jan/19 } & 2019 \\ \text { BRADESCO } & 8,63 & 1,76 & 2,6 & 2,68 & 1,2 & 1,29 & 4,57 & 0,3 & 0,4 & -0,18 & -1,24 & 7,14 & 32,77 \% \\ \text { ANTANDER } & 7,81 & 1,31 & 1,96 & 2,05 & 1,2 & 1,26 & 3,63 & 1,2 & 1,95 & -0,25 & -1,86 & 8,81 & 32,65 \% \\ \text { ISE } & 10,44 & 5,13 & -0,42 & 2,04 & 2,21 & 3,78 & 2,82 & 2,5 & -0,19 & -3,94 & -3,53 & 9,19 & 31,58 \% \\ \text { Ibovespa } & 6,85 & 0,95 & 2,36 & 3,57 & -0,67 & 0,84 & 4,06 & 0,7 & 0,98 & -0,18 & -1,86 & 10,82 & 33,19 \%\end{array}$

Fonte: Elaboração própria a partir de dados disponibilizados pelo Quantum Axis (2021)

Desde 2019, o Bradesco Sustentabilidade acumula retornos superiores ao Santander Seleção, tendo apresentado no período de 01/01/2019 até 30/04/2021, um retorno absoluto de 27,46\%, contra 13,28\% do Santander. Em 2020, ano turbulento para o mercado financeiro e para o mundo, os dois fundos não geraram alpha, porém, o fundo sustentável demonstrou uma recuperação mais acentuada e fechou o ano negativo em 1,04\%, enquanto o Santander apresentou uma rentabilidade de $-6,12 \%$. 
Sharpe:

Tabela 24: Sharpe

\begin{tabular}{|c|c|c|c|}
\hline \multicolumn{4}{|c|}{ Sharpe $-22 / 05 / 2019$ até 21/05/2021 } \\
\hline Nome & Volatilidade & Retorno & Shualizado no periodo \\
\hline BRADESCO & $33,68 \%$ & $12,49 \%$ & $\mathbf{0 , 2 6}$ \\
\hline SANTANDER & $32,69 \%$ & $6,84 \%$ & $\mathbf{0 , 1}$ \\
\hline Ibovespa & $31,58 \%$ & $13,91 \%$ & $\mathbf{0 , 3 1}$ \\
\hline ISE & $33,19 \%$ & $14,35 \%$ & $\mathbf{0 , 3 3}$ \\
\hline CDI & $0,10 \%$ & $3,58 \%$ & $\mathbf{0}$ \\
\hline
\end{tabular}

Fonte: Elaboração própria a partir de dados disponibilizados pelo Quantum Axis (2021)

Para o cálculo de cada um dos índices de Sharpe dos fundos escolhidos, foi utilizada a fórmula:

$\mathrm{IS}=(\mathrm{Ri}-\mathrm{Rf}) /(\sigma \mathrm{i})$

Sendo Ri o retorno do ativo analisado, Rf o retorno livre de risco e o desvio padrão é o risco do ativo.

BRADESCO SUSTENTABILIDADE: IS $=(0,1249-0,0358) /(0,3368)->$ $\mathrm{IS}=0,26$

SANTANDER SELEÇÃO: IS = $(0,684-0,0358) /(0,3269)$-> IS =0,10

Observando esses dados, notamos que ambos os fundos performaram abaixo dos índices de referência, Ibovespa e ISE, e consequentemente, também tiveram um Sharpe ratio menor. O fundo do Bradesco apresentou 0,26 e o do Santander 0,10, demonstrando que novamente, o fundo com estratégia ESG conseguiu superar o que possui estratégia normal, dessa vez os dois são geridos por grandes bancos brasileiros. 
Drawdown:

Tabela 25: Drawdown

\begin{tabular}{|c|c|c|c|c|c|}
\hline \multicolumn{6}{|c|}{ Drawdown - 22/05/2019 à 21/05/2021 (diária) } \\
\hline Ativo & Retorno & Volatilidade & $\begin{array}{l}\text { Início do Máximo } \\
\text { Drawdown }\end{array}$ & $\begin{array}{l}\text { Data do Máximo } \\
\text { Drawdown }\end{array}$ & $\begin{array}{l}\text { Máximo } \\
\text { Drawdown }\end{array}$ \\
\hline BRADESCO & $26,54 \%$ & $33,68 \%$ & $23 / 01 / 2020$ & $23 / 03 / 2020$ & $-47,36 \%$ \\
\hline SANTANDER & $14,14 \%$ & $32,69 \%$ & $23 / 01 / 2020$ & $23 / 03 / 2020$ & $-48,30 \%$ \\
\hline CDI & $7,28 \%$ & $0,10 \%$ & & & \\
\hline Ibovespa & $29,75 \%$ & $33,86 \%$ & $23 / 01 / 2020$ & $23 / 03 / 2020$ & $-46,82 \%$ \\
\hline ISE & $30,75 \%$ & $32,68 \%$ & $23 / 01 / 2020$ & $23 / 03 / 2020$ & $-43,86 \%$ \\
\hline
\end{tabular}

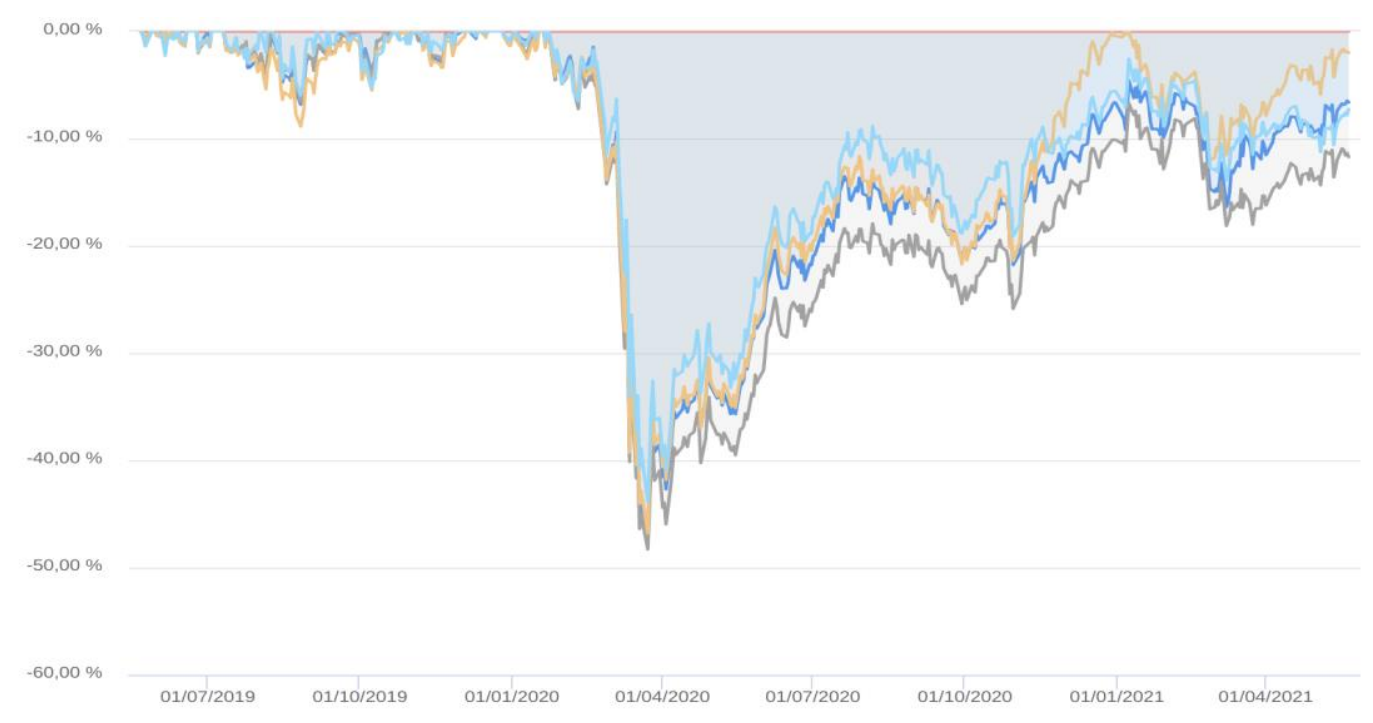

Fonte: Elaboração própria a partir de dados disponibilizados pelo Quantum Axis

Assim como nas assets independentes, os fundos de grandes bancos também sofreram grandes perdas em 2020, decorrentes das incertezas provocadas pelo Coronavírus.

Desde a cota máxima do Bradesco Sustentabilidade, o fundo recuou 47,36\%, tendo o drawdown iniciado em 23/01/2020 e o seu auge no dia 23/03/2021, data em que os mercados globais sofreram grandes quedas.

O fundo gerido pelo Santander também foi afetado, e teve um drawdown ainda maior, número que a 48,30\% desde sua cota máxima. As datas de cota máxima e queda máxima foram as mesmas em ambos os fundos.

Tantos fundos com exposição ESG quanto os mais tradicionais sofreram na queda, contudo, observando o gráfico, novamente é possível perceber que a 
estratégia ESG se saiu melhor no cenário de recuperação, com o Bradesco apresentando uma melhor rentabilidade.

Treynor:

Tabela 26: Treynor

\begin{tabular}{|c|c|c|c|c|}
\hline & \multicolumn{4}{|c|}{ 22/05/2019 até 21/05/2021 } \\
\hline Nome & Retorno Médio & $\begin{array}{r}\text { Beta - } \\
\text { CDI/Ibovespa }\end{array}$ & $\begin{array}{c}\text { Beta - } \\
\text { CDI/ISE }\end{array}$ & $\begin{array}{c}\text { Treynor - } \\
\text { CDI/Ibovespa }\end{array}$ \\
\hline BRADESCO & $0,07 \%$ & 0,98 & 1 & $\mathbf{0 , 1 4 3 8 5 9}$ \\
SANTANDER & $0,05 \%$ & 0,95 & 0,96 & $\mathbf{0 , 0 8 9 8 1 6}$ \\
CDI & $0,01 \%$ & 0 & 0 & \\
Ibovespa & $0,07 \%$ & 1 & 1 & $\mathbf{0 , 1 5}$ \\
ISE & $0,07 \%$ & 0,93 & 1 & $\mathbf{0 , 1 7}$ \\
\hline
\end{tabular}

Fonte: Elaboração própria a partir de dados disponibilizados pelo Quantum Axis (2021)

Para calcular o Treynor de cada um dos fundos, foi utilizado o retorno médio diário de cada um dos indicadores, o benchmark escolhido foi o Ibovespa e o ativo livre de risco o CDI.

$\mathrm{IT}=(\mathrm{Ra}-\mathrm{Rf}) /(\mathrm{Ba})$

Bradesco: $\mathrm{IT}=(0,07 \%-0,01 \%) / 0,98=0,000570867$

Santander: $\mathrm{IT}=(0,05 \%-0,01 \%) / 0,95=0,000352279$

Com o Treynor diário calculado, utilizou-se o período de 252 dias para chegar no valor do indicador ao ano.

Assim, chegamos nos valores 0,143859 (14,38\%) para o Bradesco e 0,089816 (8,98\%) para o Santander. Portanto, o fundo ESG teve uma eficiência de $14,38 \%$ com o risco sistêmico considerado, sendo mais eficiente do que o tradicional. 
Sortino:

Tabela 27: Sortino
\begin{tabular}{|c|c|c|c|c|c|}
\hline \multicolumn{7}{|c|}{$\begin{array}{c}\text { Nome } \\
\text { Notorno } \\
\text { Médio } \\
\text { Diario }\end{array}$} & $\begin{array}{c}\text { Downsid } \\
\text { e Risk - } \\
\text { CDI }\end{array}$ & $\begin{array}{c}\text { Retorno } \\
\text { Excedente }\end{array}$ & $\begin{array}{c}\text { Sortino - } \\
\text { Diaria - } \\
\text { CDI }\end{array}$ & $\begin{array}{c}\text { Sortino no } \\
\text { Periodo - } \\
\text { CDI }\end{array}$ \\
\hline BRADESCO & $0,07 \%$ & $1,62 \%$ & $0,06 \%$ & $3,43 \%$ & $\mathbf{0 , 5 4 4 9 2 3}$ \\
SANTANDER & $0,05 \%$ & $1,60 \%$ & $0,03 \%$ & $2,12 \%$ & $\mathbf{0 , 3 3 6 5 9}$ \\
Ibovespa & $0,07 \%$ & $1,61 \%$ & $0,06 \%$ & $3,78 \%$ & $\mathbf{0 , 6 0 0 1 5 5}$ \\
ISE & $0,07 \%$ & $1,57 \%$ & $0,06 \%$ & $3,88 \%$ & $\mathbf{0 , 6 1 5 6 7 5}$ \\
\hline
\end{tabular}

Fonte: Elaboração própria a partir de dados disponibilizados pelo Quantum Axis

O índice Sortino dos fundos dos grandes bancos, assim como os fundos de assets independentes, foi calculado utilizando o CDI como ativo livre de risco.

$\mathrm{Is}=((\mathrm{Ri}-\mathrm{Rf}) /(\sigma$ dos retornos negativos $)) *\left((252)^{\wedge}(1 / 2)\right)$

Bradesco: Isa $=(0,0697 \%-0,0139 \%) / 1,6248 \%=3,4326 \% *\left((252)^{\wedge}(1 / 2)\right)$ $=54,4923 \%$ a.a

Santander: Isa $=(0,0479 \%-0,0139 \%) /(1,6030 \%+=2,1203 \% *((252) \wedge$ $(1 / 2))=\mathbf{3 3}, \mathbf{6 5 9 0} \%$ a.a

Portanto, seguindo o objetivo do indicador, que é medir a relação entre risco e retorno do fundo considerando somente as oscilações negativas no período, o fundo sustentável do Bradesco foi muito superior ao Santander, mostrando que apresenta uma maior capacidade de se proteger de quedas e mitigando o risco de grandes oscilações negativas no portfólio.

Assim como no caso das assets independentes, dentro dos grandes bancos é possível obter fundos ESG que desempenharam melhor que fundos tradicionais. 


\section{Conclusão}

Este trabalhou pretendeu investigar e comparar dados de fundos de investimentos sustentáveis, que possuem em seu mandato de gestão os conceitos de Environmental Social and Governance e gerar um lucro consciente ao investidor, com fundos de investimentos tradicionais que não fazem nenhum tipo de apologia ao tema na sua gestão. Para auxiliar a comparação foram utilizados três benchmarks, sendo eles o CDI, Ibovespa e o ISE.

O tema ESG ganhou relevância nos últimos anos, uma vez que os investimentos com retornos altos na renda fixa estão escassos no mercado devido a redução da SELIC. O investidor, visando maiores retornos, passou a olhar com mais atenção para produtos que investem em renda variável e que de alguma forma, estejam contribuindo positivamente para a sociedade.

Para auxiliar a análise e atingir o objetivo pretendido, foi utilizado o livro de Assaf Neto (2014), do qual foram retirados os conceitos do sistema financeiro nacional e utilizados na análise dos fundos. Os dados quantitativos foram retirados da plataforma Quantum Axis e calculados através do Excel, a fim de justificar o raciocínio e a conclusão deste estudo.

Ao se tratar de sustentabilidade, o Brasil ainda está atrasado em relação a países desenvolvidos, como os Estados Unidos e grande parte da União Europeia, isso se reflete também no mercado financeiro. A quantidade de produtos sustentáveis ainda é muito pequena, uma vez que as empresas passaram a adotar as medidas ESG há pouco tempo e não tinham estímulos para isso, porém, a incorporação de fatores socioambientais pelo setor corporativo será cada vez mais necessária.

No modelo liberal em que vivemos, antigamente achava-se moral a escravidão de seres humanos para realizar trabalhos que aqueciam a economia, hoje isso é considerado uma atrocidade, provavelmente, as gerações futuras, ao se depararem com os efeitos do aquecimento global de forma mais contundente, também acharão uma atrocidade a maneira como consumimos os recursos e o descaso com que lidamos com o meio ambiente. A questão climática que vivemos hoje é um problema de longo prazo, há mais de cem anos emitimos gás carbônico na atmosfera e continuaremos emitindo pelos próximos anos, portanto, as empresas 
cada vez mais devem aderir aos padrões ambientais propostos na metodologia ESG ou as gerações futuras sofrerão impactos implacáveis.

Observado a rentabilidade e indicadores dos fundos apresentados, em 2020, notamos que empresas que adotam as boas práticas tiveram seu valor de mercado recuperado mais rapidamente após a pandemia, com os fundos sustentáveis se recuperando do drawdown mais rapidamente. Ainda que se tratando de um universo restrito no Brasil de empresas listas e ESG, o Constellation Compounders em 2020 teve uma rentabilidade acumulada de $19,96 \%$, sendo muito superior a todos os fundos comparados e aos próprios índices de mercado, como o ISE e o Ibovespa. Ele foi também o fundo que teve a melhor performance no período inteiro analisado, gerando um alpha absoluto de $62,11 \%$.

Portanto, como conclusão do estudo atualmente o investidor brasileiro é capaz de encontrar produtos de investimentos sustentáveis que apresentem uma relação de risco e retorno superior a fundos tradicionais e que gerem valor a sociedade, uma vez que em todos os indicadores apresentados, os fundos ESG foram superiores aos comparados, sendo importante ressaltar que a rentabilidade passada dos fundos não é garantia de performance positiva no futuro. 


\section{Referências bibliográficas}

ANBIMA. Raio-x do investidor brasileiro. São Paulo, 2019. Disponível em:

<https://www.anbima.com.br/data/files/25/50/2D/8C/0BBB96109FF4F696

A9A80AC2/RaioX_investidor_2019.pdf > . Acesso em: 05 de abril de 2021.

ASSAF NETO, A. Mercado Financeiro. 12 ed. São Paulo: Atlas, 2014.

B3. Histórico. Disponível em: <https://ri.b3.com.br/pt-br/b3/historico/>.

B3. Quem somos. Disponível em: <http://www.b3.com.br/pt br/b3/institucional/quem-somos/>.

BRADESCO. Nossa história. Disponível em: https://www.bradescoasset.com.br/SiteBram/ptbr/A-BRAM/Quem-Somos

BRADESCO. Relatório integrado versão resumida 2020. Disponível em: $<$ https://api.mziq.com/mzfilemanager/v2/d/80f2e993-0a30-421a-9470a4d5c8ad5e9f/e23f926c-04f3-4716-ecdd-fa835a3297d5?origin=2> .

Brigham e Ehrhardt Administração Financeira: Teoria e Prática ; (2012)

Constellation. Compounders ESG. Disponível em: <https://constellation.com.br/pra-voce/compounders-esg/>.

Constellation. Constellation Compounders ESG. https://constellation.com.br/wp-content/uploads/2021/05/Abril-2021-

Constellation-Compounders-ESG.pdf

Constellation. ESG. Disponível em: <https://constellation.com.br/esg/>.

Constellation. Sobre. Disponível em: https://constellation.com.br/pordentro/sobre/

Disponível

em:

<http://www.ipeadata.gov.br/exibeserie.aspx?serid=38402>.

Estadão. Rede social vira espaço de 'gurus' em finanças. Disponível em: < https://economia.estadao.com.br/noticias/geral,rede-social-viraespaco-de-gurus-em-financas,70003401067/>. Acesso em: 24 de outubro de 2020.

HALFELD, Mauro; TORRES, Fábio de Freitas Leitão. Finanças comportamentais: a aplicações no contexto brasileiro. Rev. adm. Empresas, São Paulo, v. 41, n. 2, p. 64-71, 2001.

IPEA Data. Taxa de juros nominal - Overnight / Selic. IPEA Data, 24/10/2020.

ISEB3. O que é ISE B3. Disponível em: <http://iseb3.com.br/o-que-e-o-is>. 
JPG. JGP ESG FIA. Disponível em: $<$ https://dashboard.jgp.com.br/documents/jgp-esg-fic-fia-relatoriocomercial-36.pdf>.

JPG. JGP ESG FIC FIA. Disponível em: <https://www.jgp.com.br/fundoperfil?slug=igp-esg-fic-fia>.

PAK, Esther. Are Your Fund's Returns Worth the Downside Volatility?. Morningstar. Disponível em: $<$ https://www.morningstar.com/articles/383588/are-your-funds-returnsworth-the-downside-volatility >.

PARANÁ. Edemilson; A digitalização do mercado de capitais no Brasil: Tendencias recentes, 2016.

Santader Asset Management. 20 anos de investimento ESG. Disponível em: $\quad<$ https://santanderassetmanagement.com.br/investimentoresponsavel2/investimento-responsavel>.

Valor investe. Bolsa divulga empresas do índice de sustentabilidade de 2021. Veja a lista. Disponível em: $<$ https://valorinveste.globo.com/mercados/renda-variavel/bolsas-eindices/noticia/2020/12/01/bolsa-divulga-empresas-do-indice-desustentabilidade-de-2021-veja-a-lista.ghtml>.

Valor investe. Conheça os fundos de investimentos ESG ou de impacto disponíveis no Brasil. Disponível em: $<$ https://valorinveste.globo.com/produtos/fundos/noticia/2021/03/07/conhe ca-os-fundos-de-investimentos-esg-ou-de-impacto-disponiveis-nobrasil.ghtml>.

Valor Investe. Número de pessoas físicas na bolsa cresce ainda mais em agosto e encosta em 3 milhões. Setembro de 2020.Disponível em: $<$ https://valorinveste.globo.com/mercados/rendavariavel/noticia/2020/09/02/numero-de-pessoas-fisicas-na-bolsa-cresceainda-mais-em-agosto-e-encosta-em-3-milhoes.ghtml>. Acesso em: 24 de outubro de 2020.

Valor Investe. Para onde caminham as plataformas de investimentos?. Disponível em: <https://valorinveste.globo.com/educacaofinanceira/noticia/2019/07/25/para-onde-caminham-as-plataformas-deinvestimentos.ghtml >.Acesso em: 24 de outubro de 2020. 